\title{
Dynamics of the West African Monsoon. Part IV: Analysis of 25-90-Day Variability of Convection and the Role of the Indian Monsoon
}

\author{
Serge Janicot, ${ }^{*}$ Flore Mounier, ${ }^{+}$Nicholas M. J. Hall, ${ }^{\#}$ StéPhanie LerouX, $@$ \\ BENJAMIN SUlTAN,* AND GEORGE N. Kiladis\& \\ *LOCEAN/IPSL, IRD, UPMC, Paris, France \\ ${ }^{+}$EQECAT, Paris, France \\ \#LEGOS, UPS, Toulouse, France \\ ${ }^{\circledR}$ LTHE, UJF, Grenoble, France \\ \& Physical Sciences Division, Earth System Research Laboratory, NOAA, Boulder, Colorado
}

(Manuscript received 6 November 2007, in final form 5 September 2008)

\begin{abstract}
This paper is part of a series of studies addressing the dynamics of the West African summer monsoon at intraseasonal time scales between 10 and 90 days. The dominant mode of 25-90-day convective variability in the African monsoon was investigated, starting from previous results involving the excitation of dry equatorial Kelvin and Rossby waves by a negative diabatic heat source located over the warm pool. This evolution is consistent with a significant contribution by a convectively coupled equatorial Rossby wave and the MJO. On the other hand, convectively coupled Kelvin waves as well as the dry Kelvin wave signal have a very weak impact. However, there is more to the global control of the African summer monsoon than convectively coupled wave dynamics. The active/break cycle of the Indian monsoon, controlled by a northward-moving dipole of diabatic heating in the Indian sector, can also influence the African monsoon through atmospheric teleconnections. Simulations performed with a dry primitive equation model show that this influence may be transferred through the northern Indian heat source, which excites a Rossby cyclonic circulation propagating westward over North Africa that is cut off by the northward arrival of the equatorial Indian heat source and the associated intrusion of an anticyclonic ridge. Low-level westerly winds and moisture advection within the ITCZ consequently increase over Africa. The mean time lag between an active phase over India and over Africa is about $15-20$ days.
\end{abstract}

\section{Introduction}

The central and West African region depends heavily on rainfall during the summer monsoon season, which corresponds to the northernmost migration of the intertropical convergence zone (ITCZ) (Hastenrath 1991). A large amount of work has already been completed on rainfall variability of the African monsoon, through studies from mesoscale convective systems (Laing and Fritsch 1993, 1997; Hodges and Thorncroft 1997; Mathon and Laurent 2001; Mathon et al. 2002), synoptic-scale easterly waves (Reed et al. 1977; Thompson et al. 1979; Duvel 1990; Thorncroft and Hoskins 1994a,b; Diedhiou

Corresponding author address: Dr. Serge Janicot, LOCEAN/ IPSL, Université Pierre et Marie Curie, Boite 100, 4 Place Jussieu, 75252 Paris CEDEX 05, France.

E-mail: serge.janicot@locean-ipsl.upmc.fr et al. 1999; Kiladis et al. 2006; Hall et al. 2006), and convectively coupled Kelvin waves (Mekonnen et al. 2008; Mounier et al. 2007) to interannual and decadal time scales mainly linked to tropical sea surface temperature (SST) anomaly patterns (Lamb 1978a,b; Nicholson 1978; Newell and Kidson 1984; Folland et al. 1986; Rowell et al. 1995; Ward 1998; Janicot et al. 2001; Rowell 2001; Giannini et al. 2003).

The intraseasonal time scale variability of rainfall and convection in the African monsoon has also been studied in recent years. Janicot and Sultan (2001) and Sultan et al. (2003) examined the importance of 10-25 and 25-60 day periodicities in rainfall and convective activity over the Sahel. Mounier and Janicot (2004) extended this work by carrying out an EOF analysis on convection fields during northern summer over West and central Africa and showed evidence of two independent modes of variability in the 10-25-day range. 
The first is characterized by a stationary and uniform modulation of convection within the African ITCZ. It is associated with a modulation of the zonal low-level wind over the equatorial Atlantic and a zonal dipole of convection between Africa and the north equatorial Atlantic off the coast of South America (Mounier et al. 2008). The second is a westward propagating signal from eastern Africa to the western tropical Atlantic, consistent with the signal already detected over the Sahel (Sultan et al. 2003).

On a global scale the dominant mode of intraseasonal variability is the Madden-Julian oscillation (MJO) (Madden and Julian 1994). The MJO is characterized by eastward-propagating convective and SST anomalies over the warm pool sector and associated global circulation anomalies with one complete cycle lasting between approximately 30 and 60 days (Knutson and Weickmann 1987; Rui and Wang 1990; Matthews 2000). Knutson and Weickmann (1987) and Annamalai and Slingo (2001) found a weak convective signal over Africa in their northern summer MJO life cycles such that enhanced convection over Africa coincides with enhanced convection over the equatorial Indian Ocean. Whereas other studies show nonexistent signal over Africa (Knutson et al. 1986; Murakami et al. 1986; Maloney and Hartmann 2000), Matthews (2004) shows that the remote response to the MJO over the warm pool sector offers a plausible explanation for the dominant mode of variability in convection over West and central Africa at 20-200-day time scales. Twenty days prior to an enhancement of convection over Africa, convection is reduced over the equatorial warm pool. In response to this change in warm pool convection, a dry equatorial Kelvin wave propagates rapidly eastward and an equatorial Rossby wave response propagates westward: Between them they complete a circuit of the equator and meet up 20 days later over Africa, favoring an enhancement of deep convection. The Kelvin wave has an average speed $\left(33 \mathrm{~m} \mathrm{~s}^{-1}\right)$, similar to the dry wave speed detected by Milliff and Madden (1996) over the equatorial eastern Pacific. These dry modes should be distinguished from their convectively coupled counterparts, which propagate at a much slower phase speed (12-18 $\mathrm{m} \mathrm{s}^{-1}$ ). In addition, the equatorial Rossby wave seems too fast $\left(19 \mathrm{~m} \mathrm{~s}^{-1}\right)$ to correspond to the linear wave theory (Gill 1980), which could be explained by effects of the background mean winds or interaction with convection and orography. Matthews' results have been recently confirmed by Maloney and Shaman (2008) using TRMM precipitation and National Centers for Environmental Prediction (NCEP)-National Center for Atmospheric Research (NCAR) reanalysis: they show that the MJO explains about 30\% of 30-90-day precipitation variance in the West African monsoon region.

During northern summer the MJO also strongly interacts with the Asian monsoon through northward propagation of convective and circulation anomalies from the equatorial Indian Ocean to the Himalayas (Yasunari 1981), leading to the active/break phases of the monsoon over India (Goswami and Ajaya Mohan 2001; Annamalai and Slingo 2001). Independent of the MJO activity in the Indian sector, Rodwell and Hoskins (1996) showed that the convective activity in the summer Indian monsoon can have a remote effect over northern Africa. The integration of a global dry hydrostatic primitive equation model with prescribed constant idealized Indian monsoon diabatic-heating field forcing centered at $25^{\circ} \mathrm{N}, 90^{\circ} \mathrm{E}$ shows a westward-moving Rossby wave solution in the Northern Hemisphere inducing warm subsidence that expands over northeastern Africa.

This paper is part of a series of studies addressing the dynamics of the West African summer monsoon at intraseasonal time scales between 10 and 90 days (Sultan et al. 2003; Sultan and Janicot 2003; Mounier and Janicot 2004; Mounier et al. 2008). In this paper we investigate the 25-90-day variability of convection in the African monsoon, starting from the results of Matthews (2004). The datasets are detailed in section 2. In section 3 we analyze the dominant mode of convection over Africa in the 25-90-day time scale. This signal is similar to the one detected by Matthews (2004) and Maloney and Shaman (2008), and we show also that it is characterized by a westward propagation over Africa. Related composite fields over the whole tropics are computed. This suggests that there is more to the global control of the African summer monsoon than dry equatorial Kelvin and Rossby waves emanating from the MJO over the warm pool sector. The active/break cycle of the Indian monsoon seems to remotely impact the African monsoon through teleconnections controlled by diabatic heat sources in the Indian sector. The way this influence is transmitted is investigated through filtering computations and modeling experiments in section 4 . Conclusions are given in section 5.

\section{Datasets}

\section{a. The NCEP-DOE AMIP-II Reanalysis}

The NCEP-NCAR reanalysis dataset (Kalnay et al. 1996) provides a gridded analysis of the global observational network of meteorological variables (wind, temperature, geopotential height, humidity on pressure levels, surface variables) and flux variables such as precipitation rate and radiative and turbulent fluxes. The 
reanalysis uses a "frozen" state-of-the-art analysis and forecast system at a triangular spectral truncation of T62 to perform data assimilation throughout the period 1948 to present. Data are reported on a $2.5^{\circ} \times 2.5^{\circ}$ grid every $6 \mathrm{~h}(0000,0600,1200$, and 1800 UTC), for 17 pressure levels from 1000 to $10 \mathrm{hPa}$ as well as the surface level, which are adequate resolutions for studying synoptic weather systems. The NCEP-Department of Energy (DOE) Atmospheric Model Intercomparison Project II (AMIP-II) Reanalysis (R-2) dataset-the updated version of the NCEP-NCAR reanalysis-has been used here with one value per day by averaging the four outputs of each day. This version of the reanalysis shows significant improvement over the original, especially for land surface parameters and surface-air fluxes (Kanamitsu et al. 2002).

\section{b. The NOAA OLR dataset}

Since 1974, polar orbital Television and Infrared Observation Satellite (TIROS) missions of NOAA satellites have established a quasi-complete series of twicedaily outgoing longwave radiation (OLR), at the top of the atmosphere and at a resolution of $2.5^{\circ}$ latitude/ longitude (Grueber and Krueger 1984). The daily interpolated OLR dataset produced by the Climate Diagnostic Center (Liebmann and Smith 1996) has been used over the period 1979-2000 as a proxy for deep convection. Local times of the measurements varied during the period 1979-90 between 0230 and 0730 and again between 1430 and 1930 local time. Since deep convection over West Africa has a strong diurnal cycle, a sample of daily OLR based on two values separated by $12 \mathrm{~h}$ is obtained to get a daily average. Wheeler et al. (2000), Straub and Kiladis (2002), and Roundy and Frank (2004a), among others, have illustrated the utility of OLR in tracing convectively coupled equatorial waves.

\section{Detection of the 25-90-day-period variability of convection}

\section{a. SEOF analysis on the Africa domain}

Sultan et al. (2003) showed that intraseasonal variability of convection over West and central Africa can be separated into two ranges of periodicities: lower and higher than approximately 25 days. So, to investigate convective variability over Africa linked to the MJO, a spatial empirical orthogonal function (SEOF) analysis (Richman 1986) has been performed on the 25-90-day bandpass filtered June-September OLR values over the domain $10^{\circ} \mathrm{S}-30^{\circ} \mathrm{N}, 30^{\circ} \mathrm{W}-30^{\circ} \mathrm{E}$ for the period 1979 2000. The first mode (SEOF1) explains $20.4 \%$ of the $25-$ 90-day filtered variance and is retained as it passes both the scree (Cattell 1966) and North (North et al. 1982) tests. It is clearly separated from SEOF2 and SEOF3, which are also significant but explain only $8.6 \%$ and $7.8 \%$ of the variance and will not be considered further (see Matthews 2004). The time series of the principal component (PC) of the first mode has been used to produce a composite analysis, presented in Fig. 1. The 25-90-day filtered OLR (contours) composite map is shown for strong (35 cases) minus weak (33 cases) convective intraseasonal events. Strong (weak) events are selected when the respective PC time series values are maximum (minimum) and greater (lower) than the PC standard deviation. The number of cases selected represents approximately three peaks per season (122 days), either positive or negative. This composite sequence is displayed from $t_{0}-10$ days to $t_{0}+10$ days with a 2-day lag, where $t_{0}$ is the reference day for the cases considered. The pattern at $t_{0}$ is very similar to the pattern extracted by Matthews (2004) and shows an enhancement of convection (negative OLR values) over most of West and central Africa of over $15 \mathrm{~W} \mathrm{~m}^{-2}$, peaking at $25 \mathrm{~W} \mathrm{~m}^{-2}$ over the Cameroon highlands. This spatial pattern is collocated with the climatological mean of the ITCZ OLR field (in summer the ITCZ is centered along $10^{\circ} \mathrm{N}$ ), resulting in a modulation of convective activity within the ITCZ without any significant changes in the latitudinal location of the ITCZ. To the east and west of the negative OLR pole, weak positive OLR anomalies are centered at $10^{\circ} \mathrm{N}, 60^{\circ} \mathrm{W}$ and at $5^{\circ} \mathrm{N}, 35^{\circ} \mathrm{E}$. The time sequence of this mode, not shown by Matthews (2004), is interesting because it highlights a very clear westward extension of the OLR anomalies on its northern part, with negative OLR anomalies beginning to occur just northeast of Lake Chad. They grow and extend westward north of $7.5^{\circ} \mathrm{N}$ up to $t_{0}$ and then dissipate to the east after $t_{0}+2$. South of $7.5^{\circ} \mathrm{N}$, the signal appears mainly as stationary, increasing and weakening simultaneously along the Guinean coast and central Africa. The corresponding unfiltered OLR sequence has a similar evolution, but the fields are a bit noisier and the anomalies are slightly stronger. This is represented on the bottom right of Fig. 1 through the evolution of OLR over the ITCZ area $\left(5^{\circ}-15^{\circ} \mathrm{N}, 20^{\circ} \mathrm{W}-\right.$ $20^{\circ} \mathrm{E}$ ) for the composite strong and weak convective event separately. We note a slight asymmetry with higher amplitude of positive OLR anomalies, indicating a higher impact of weak convective intraseasonal phases. Matthews explained the dynamics of this OLR mode in terms of a dry eastward Kelvin wave and a dry westward-propagating equatorial Rossby wave that meet over West Africa. The fact that Fig. 1 shows a dominant westward-propagating signal, at least on its 

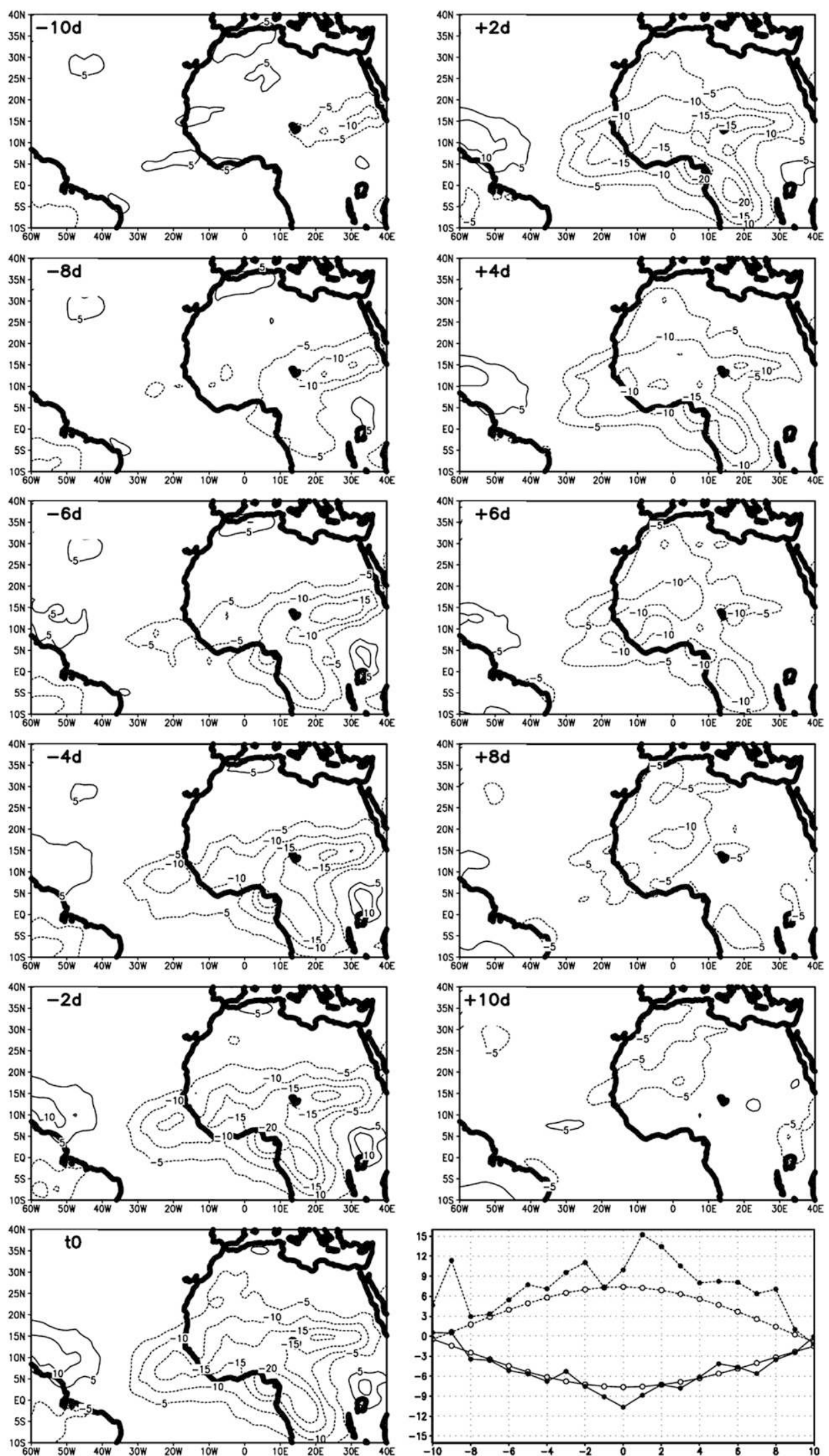
northern part, suggests that a Rossby response is an important factor.

\section{b. Composite fields on the global tropics}

To look at the global context in which the main African OLR mode evolves, Fig. 2 shows a 25-90-day filtered OLR composite field (this time represented by colors) sequence similar to that in Fig. 1 but over the whole tropical zone and from $t_{0}-20$ to $t_{0}+10$ days with a time lag of 5 days. The 25-90-day filtered geopotential heights (contour) and wind (vector) are also shown. In addition to the evolution of the dominant mode of convection over Africa described in Fig. 1, a large MJO-type signal is evident over the Indian-West Pacific sector. As shown in previous studies, this signal is characterized by two axes of propagation. There is a meridional dipole of convection moving northward. At $t_{0}-20$ a positive OLR anomaly pole is located at the equator while convection is enhanced over India, corresponding to an active phase in the Indian monsoon. The equatorial positive OLR anomaly grows and reaches India at $t_{0}-10$, consistent with the occurrence of a break in the Indian monsoon up to $t_{0}+5$. Then an active phase begins with the northward propagation of the following negative OLR anomaly. We also see an eastward propagation of these positive OLR anomalies across the tropical Pacific and toward the eastern Pacific along approximately $10^{\circ} \mathrm{N}$. This signal propagates in an east-northeastward direction at the same time as the positive OLR anomaly pole moves northward over the Indian-West Pacific sector. The positive OLR anomalies reach the coast of California and Central America at $t_{0}+5$, with their highest values at $t_{0}+10$. This evolution over the Pacific at this time scale has been very well documented and linked with the dynamics of the MJO by Maloney and Kiehl (2002). The decrease of convection off the coast of California is preceded by an opposite phase of enhanced convection at $t_{0}-10$, meaning an approximate periodicity of 40 days. Interpreting Figs. 1 and 2 together, we suggest that there are two sectors where the OLR anomaly fields appear to evolve coincidentally: 1) the Atlantic-Africa sector where a negative OLR anomaly growing over Africa is flanked by positive OLR anomalies over East Africa and over the northwestern tropical Atlantic and 2) the Indian-Pacific sector where positive OLR anomalies over the equatorial Indian basin propagate both eastward and northward, consistent with the MJO.

To better understand this evolution of the OLR anomaly fields we consider now the evolution of the 925-hPa geopotential height and wind fields. In equatorial regions, these anomalies have baroclinic vertical structures and change sign around $500 \mathrm{hPa}$. Matthews (2004) suggested that the occurrence of the main intraseasonal mode for the enhancement of convection over Africa is linked to the development, 20 days before, of a positive OLR anomaly pattern over the warm pool sector. This is associated with a suppressed MJO event that excites dry eastward propagating Kelvin and westward propagating equatorial Rossby waves, which complete a global circuit along the equator and meet over Africa. This, in turn, favors deep convection through the increase of moisture advection over Africa by low-level westerly winds over the eastern tropical Atlantic. What Fig. 2 shows is consistent with the Matthews scenario. The atmospheric pattern associated with the development of the equatorial positive OLR anomaly pattern over the warm pool at $t_{0}-15$ depicts very clearly the equatorial Kelvin-Rossby wave pattern. East of this positive OLR anomaly a positive geopotential height front propagates rapidly eastward along the equator, leading to the enhancement of lowlevel westerly winds over the whole tropical Pacific and increasing convection off the coast of California at $t_{0}-10 / t_{0}-5$. This Kelvin wave pattern has its positive geopotential height centered along the equator at $80^{\circ} \mathrm{W}$ at $t_{0}$, extending over the eastern equatorial Pacific and the western equatorial Atlantic. At $t_{0}-15$ west of the equatorial Indian positive OLR anomaly, an equatorial Rossby wave is slowly growing, characterized by a horseshoe-shaped pattern symmetric about the equator

FIG. 1. First mode of a SEOF analysis of 25-90-day filtered OLR values. Time sequence of the filtered OLR composite fields of strong minus weak convective events for JJAS 1979-2000 based on the PC time series (see details in the text); contours indicate OLR differences $\left(\mathrm{W} \mathrm{m}^{-2}\right)$. This composite sequence is displayed from $t_{0}-10$ to $t_{0}+10$ days with a 2-day lag, where $t_{0}$ is the maximum of the time series. The graph on the bottom right of the figure represents the corresponding OLR composite evolution computed over the ITCZ area $5^{\circ}-15^{\circ} \mathrm{N}, 20^{\circ} \mathrm{W}-20^{\circ} \mathrm{E}$ for a strong composite convective event through $25-90$ day filtered OLR (solid line and open circle) and unfiltered OLR (solid line and closed circle; OLR minus $225 \mathrm{~W} \mathrm{~m}^{-2}$ is represented) and for a weak composite convective event through 25-90-day filtered OLR (dashed line and open circle) and unfiltered OLR (dashed line and closed circle; OLR minus $225 \mathrm{~W} \mathrm{~m}^{-2}$ is represented). 


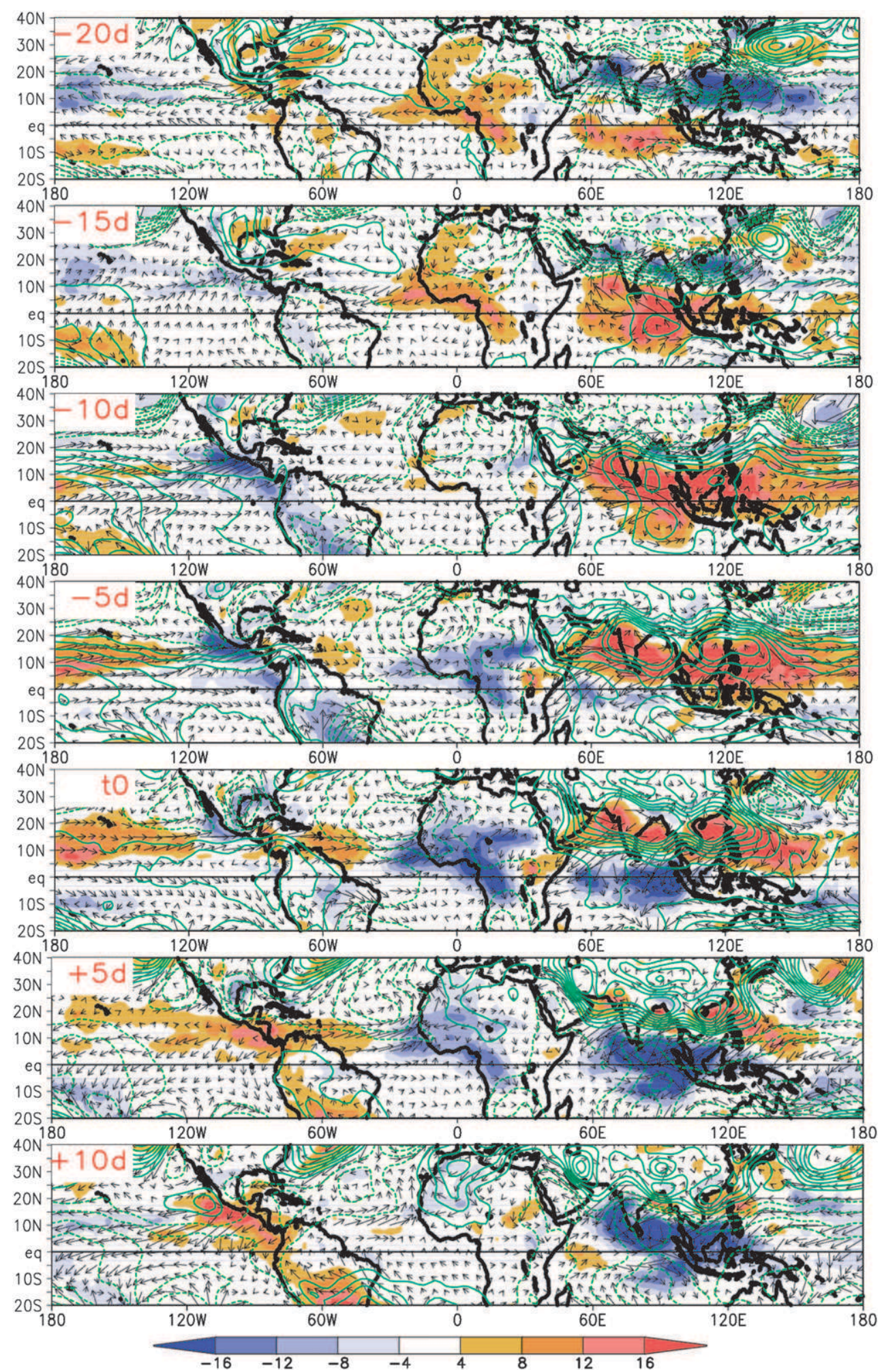

FIG. 2. As in Fig. 1 but for the 25-90-day filtered OLR (colors), 925-hPa geopotential height [solid (dashed) contours for positive (negative) values; isolines are drawn every 2 geopotential meters (gpm)], and wind (vectors: $\mathrm{m} \mathrm{s}^{-1}$; scale: $2 \mathrm{~m} \mathrm{~s}^{-1}$ for $12.5^{\circ}$ longitude) composite fields over the whole tropics from $t_{0}-20$ to $t_{0}+10$ days with a time lag of 5 days. 
with positive geopotential height anomalies developing northwestward and southwestward from the equator at $t_{0}-10 / t_{0}-5$. This westward propagation of a positive geopotential height front signifies enhanced low-level easterly winds that converge over Africa with the anomalous westerly winds linked to the Kelvin wave, helping to increase convection over equatorial Africa. These features are all consistent with the Matthews scenario.

However, Fig. 2 provides an additional element linked to the northward propagation of the convective signal over India that was not considered in the Matthews scenario. What differs from this scenario comes from the fact that the MJO also has a meridional OLR dipole component that propagates northward. This has two consequences. First, at $t_{0}-20$ we are in an active phase of the Indian monsoon with enhanced convection over northwest India, the Bay of Bengal, and the China Sea and negative geopotential height anomalies north of $10^{\circ} \mathrm{N}$ from Arabia to eastern Asia. This low-level Rossby cyclonic circulation extends westward in the following days, reaching West Africa at $t_{0}-15$, contributing to the disappearance of the positive OLR anomaly pattern at $t_{0}-10$ by enhancing westerly moisture advection inland. Second, the northward propagation of the positive OLR anomaly pole over the Indian Ocean induces a similar northward displacement of the equatorial Rossby wave pattern and the disappearance of the negative OLR anomaly pattern over India, consistent with a break phase in the Indian monsoon. This acts to cut the Africa-India belt of negative geopotential heights north of $10^{\circ} \mathrm{N}$ by enhancing the positive geopotential heights of the equatorial Rossby wave northwestward of the equatorial Indian sector, serving to isolate the low-level cyclonic circulation over Africa. From $t_{0}-10$ to $t_{0}$ the low-level cyclonic circulation propagates slowly over northern Africa, contributing to the overall enhancement of convection over Africa north of the equator and explaining the westward displacement of the OLR pattern detailed in Fig. 1. The initiation of these negative OLR anomalies northeast of Lake Chad can be explained by the low-level wind convergence between the eastern part of the African cyclonic circulation and the northwestward intrusion of the anticyclonic circulation linked to the equatorial Rossby wave. The small positive OLR anomaly located near Lake Victoria might also be consistent with the horseshoe pattern of the equatorial Rossby wave, which induces a divergence of low-level winds over this area. From $t_{0}$ to $t_{0}+10$ the low-level cyclonic circulation is located over the tropical Atlantic and goes on moving slowly westward. At $t_{0}$ it controls the westerly wind anomalies along $10^{\circ} \mathrm{N}$ over the Atlantic, consistent with the occurrence of the zonal OLR dipole between Africa and the northwestern tropical Atlantic. A similar OLR dipole has also been highlighted in the study of a quasibiweekly mode of convection detected over Africa (Mounier et al. 2008), meaning that such a regional-scale pattern is recurrent both at 10-25 and 25-90 day scales. After $t_{0}$ the negative OLR anomaly pattern over Africa dissipates owing to the greater distance from Africa of the low-level cyclonic circulation over the Atlantic and the occurrence over North Africa of positive geopotential height anomalies linked to the development of the break phase in the Indian monsoon. An anticyclonic circulation develops over India and propagates westward over North Africa. The high geopotential belt is cut off by the northwestward intrusion of negative geopotential anomalies from the equatorial Rossby waves, located over the Indian basin, resulting from the negative OLR anomalies that have propagated into the region.

\section{Analysis of the India-Africa teleconnection pattern}

Consistent with Matthews (2000, 2004), we have shown that the equatorial dynamics represented by dry Kelvin and Rossby waves emanating from the MJO has an impact on the main mode of 25-90-day variability in convection over Africa during the summer monsoon. We have also seen that there could be some atmospheric connection between the distribution of diabatic heat sources associated with the break and active phases of the Indian monsoon and the African monsoon through a pathway north of $20^{\circ} \mathrm{N}$. The way these forcings are transmitted is investigated now through filtering computations and modeling experiments. First, we will extract the filtered OLR convectively coupled signal of the MJO and of Kelvin and equatorial Rossby waves to see whether this portion of the equatorial wave spectrum can explain part of the convective activity over Africa seen in Fig. 2. Second, we will perform a set of simulations with a global dry primitive equation model forced with idealized Indian monsoon diabatic-heating fields to examine how dry Kelvin and Rossby waves emanating from these diabatic heat sources can impact the atmospheric circulation and convection over Africa.

\section{a. The detection of convectively coupled signals}

Figure 3 shows a wavenumber-frequency spectral analysis of the component of OLR symmetric about the equator between $15^{\circ} \mathrm{N}$ and $15^{\circ} \mathrm{S}$ for June-September 1979-2000. The shaded spectral peaks lie above the $95 \%$ level of significance, and a family of equivalent depth curves for Kelvin, equatorial Rossby, and inertiogravity waves from shallow-water theory (Matsuno 1966) are also shown (see Wheeler and Kiladis 1999 for 


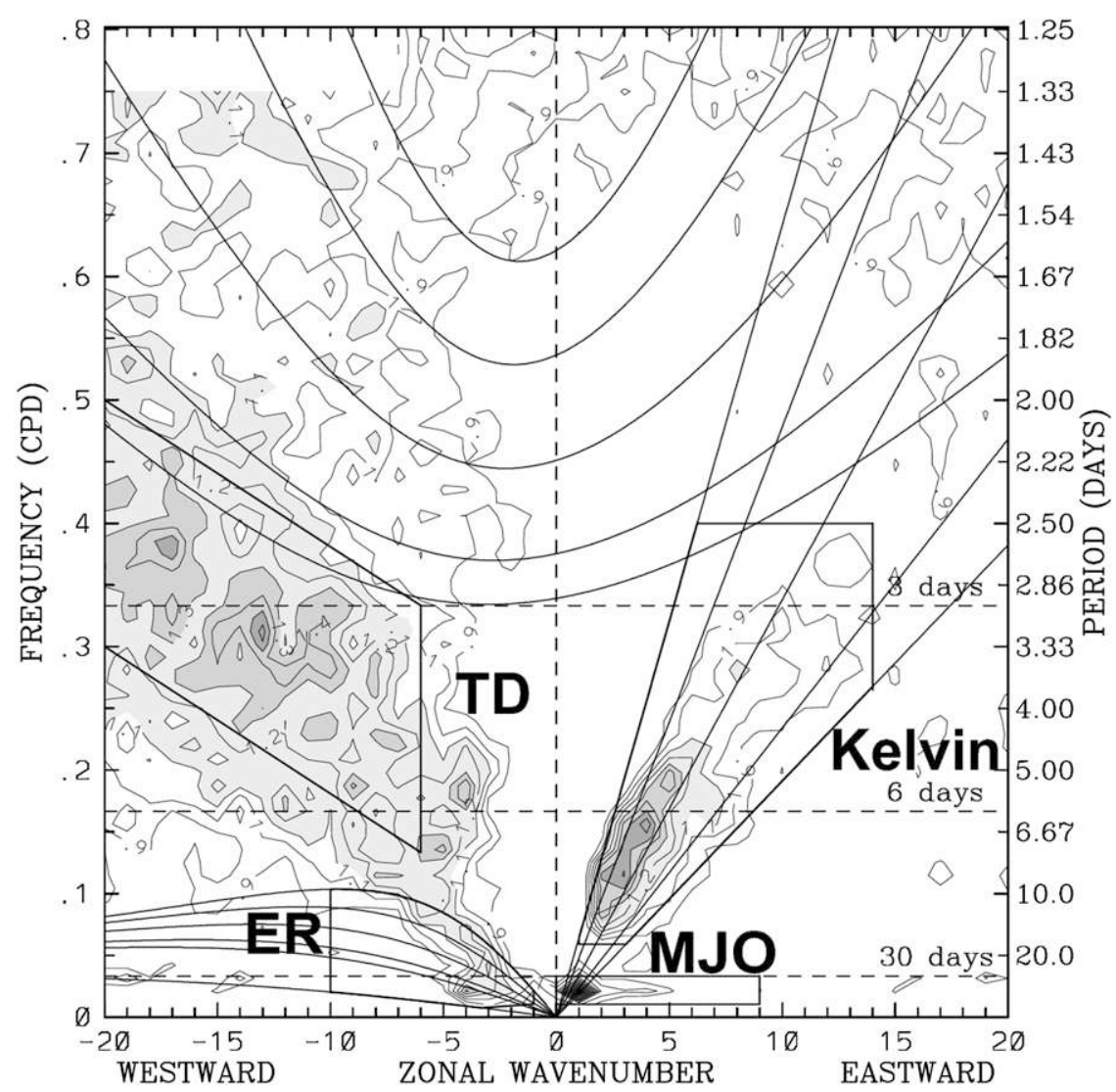

FIG. 3. Regions of wavenumber-frequency filtering calculated for June-September 19792000. Contours show the symmetric OLR power divided by a background spectrum [note that the background was calculated for the full $22 \mathrm{yr}$; see Wheeler and Kiladis (1999) for details on the computation techniques]. Contour interval of this ratio is 0.1 starting at 0.9 , with shading above 1.1 indicative of statistically significant signals. Thick boxes indicate the regions of the wavenumber-frequency domain used for filtering of the OLR dataset to retrieve the longitudetime information of these convectively coupled equatorial waves [Kelvin, tropical depression (TD), equatorial Rossby (ER), and $\mathrm{MJO}$. The thin lines are the various equatorial wave dispersion curves for the five different equivalent depths of $h=8,12,25,50$, and $90 \mathrm{~m}$ (equivalent depth of $h=1 \mathrm{~m}$ is added for ER).

more details). The spectrum reveals the existence of two peaks corresponding to Kelvin and equatorial Rossby waves lying along equivalent depth curves of around $20-50 \mathrm{~m}$. For the Kelvin wave, this corresponds to an eastward phase speed of around $15 \mathrm{~m} \mathrm{~s}^{-1}$. The MJO peak is also visible in the spectrum but does not correspond to a shallow water mode. In the Kiladis et al. (2006) paper, based on June-August data, a so-called "TD band" representing easterly waves in Africa was also identified in the domain of a westward-propagating signal between periods of 2 and 6 days and zonal wavenumbers 6 to 20 (Mounier et al. 2007). This signal will not be considered here. The boxes outline the regions of filtering for the Kelvin and Rossby waves examined here as well as the MJO signal. This filtering is performed by creating an OLR dataset through an inverse transform that retains only the Fourier coefficients corresponding to the designated boxes in Fig. 3 (Wheeler and Kiladis 1999). Note that the datasets obtained contain equatorial waves as well as a significant amount of background convection.

Figure 4 shows more sequences of composite fields, based on the difference between maxima and minima of the SEOF1 PC time series, as in Figs. 1 and 2, but for the MJO-filtered OLR signal (Fig. 4a), the Kelvin-filtered OLR signal (Fig. 4b), the equatorial Rossby-filtered OLR signal (Fig. 4c), and the sum of the three signals (Fig. 4d). The composite MJO time sequence (Fig. 4a) contains much of the signal in Fig. 2, including the northward propagation of the meridional OLR dipole in the Indian sector and the eastward propagation of the OLR signal over the whole northern tropical Pacific. 
(a)

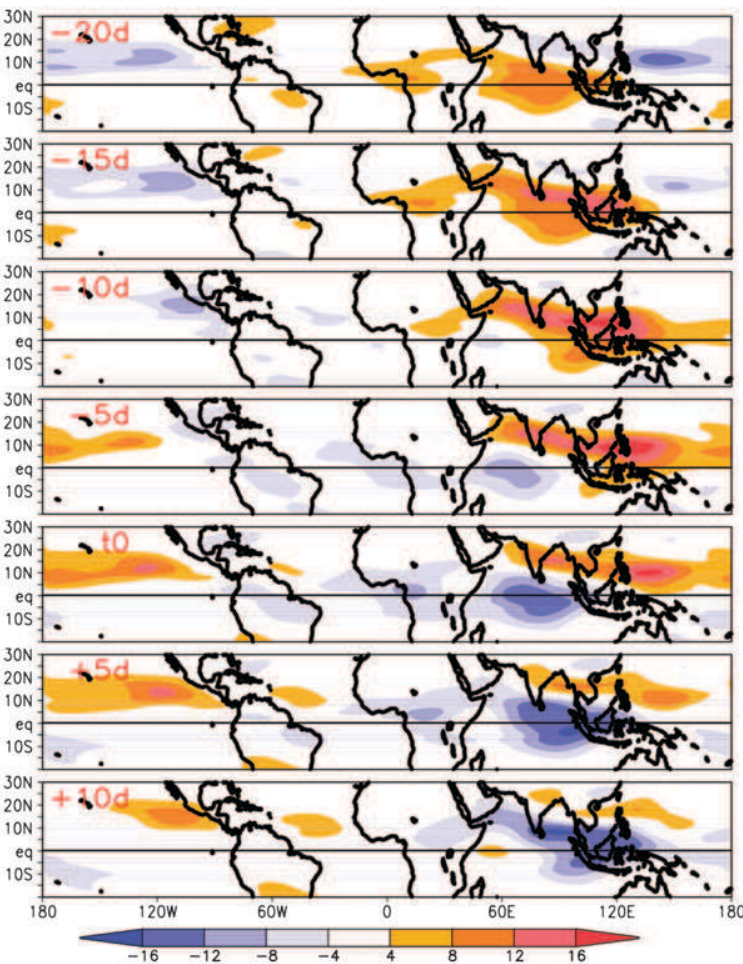

(c)
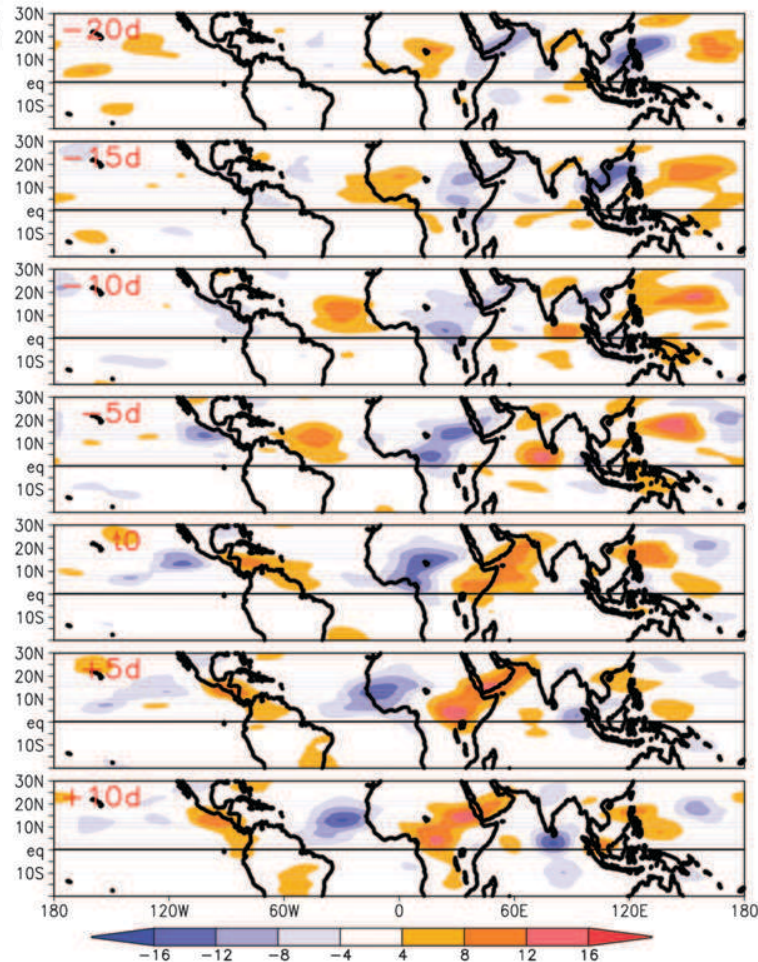

(b)
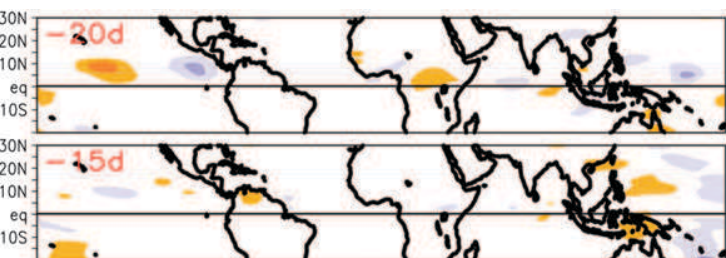

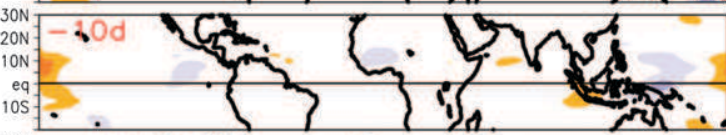

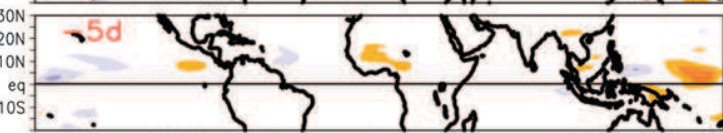

,
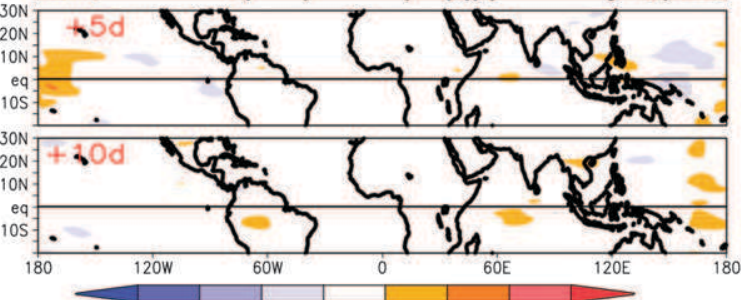

(d)
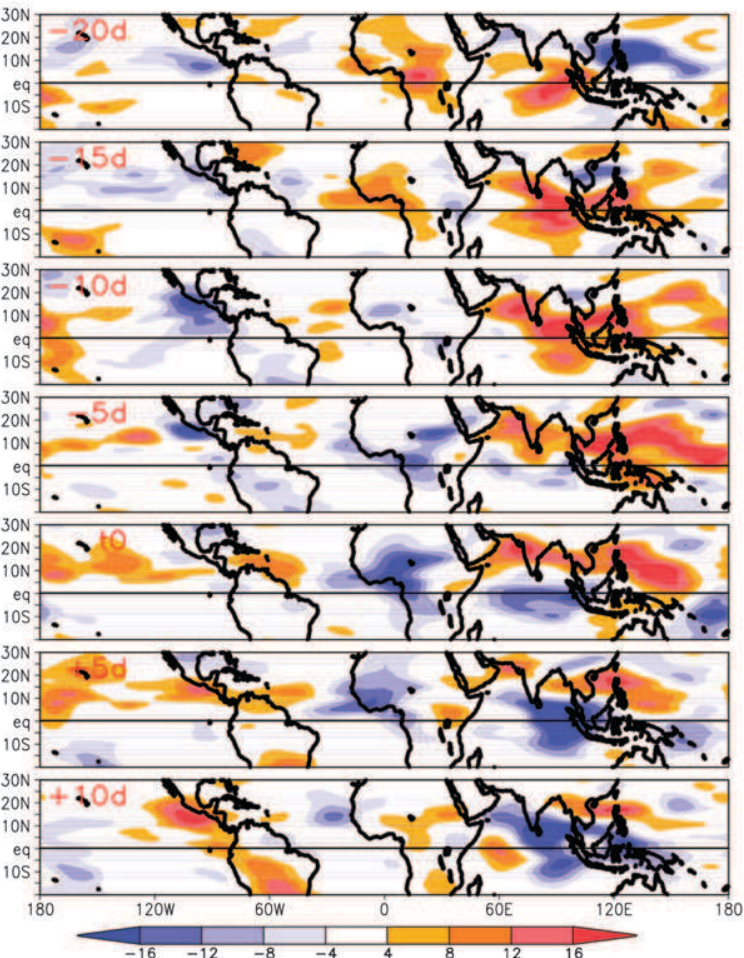

FIG. 4. As in Fig. 1 but for (a) the MJO-filtered OLR, (b) the Kelvin-filtered OLR, and (c) the equatorial Rossby-filtered OLR composite fields over the whole tropics from $\mathrm{t}_{0}-20$ to $t_{0}+10$ days with a time lag of 5 days; (d) the sum of the three signals. 
A small anomaly of OLR is evident over equatorial Africa, with its highest negative values occurring at $t_{0}$ in phase with the SEOF1 mode. The composite Kelvin time sequence (Fig. 4b) has a very weak signal. The timing of these equatorial convectively coupled waves, whose dominant periodicity is about 6 days over Africa (Mounier et al. 2007), appears to have little impact on the 25-90-day dominant mode of African convection. The equatorial Rossby time sequence (Fig. 4c) has the strongest signal propagating westward from eastern Africa to Central America along approximately $15^{\circ} \mathrm{N}$ and seems to be initiated over the equatorial Indian basin (see at $t_{0}-10$ the appearance of positive OLR poles along $80^{\circ} \mathrm{E}$, which are enhanced farther westward). It provides OLR modulation of about $15 \mathrm{~W} \mathrm{~m}^{-2}$ around the mean. As for the MJO signal, the equatorial convectively coupled Rossby signal is phased with the SEOF1 mode, with its highest negative OLR values over Africa at $t_{0}$ and its highest positive values at $t_{0}-15$ over West Africa for the preceding opposite phase and at $t_{0}+$ 10 over eastern Africa for the following one. The sum of these three signals (Fig. 4d) shows OLR patterns qualitatively similar to the total 25-90-day filtered OLR variation (Fig. 2). At $t_{0}$ it is even stronger than the 25-90-day filtered modulation (Fig. 2) and close to the unfiltered OLR modulation (see the graph on Fig. 1). Roundy and Frank (2004b) have highlighted the importance of westward-propagating equatorial Rossby modes interacting with the MJO in accounting for much of the intraseasonal convective variability within the tropics. In this case, it appears that equatorial convectively coupled Rossby wave dynamics, plus the MJO, explain most of the primary 25-90-day mode of convection over Africa. While it appears from the results in section 3 that dry Kelvin waves may also be important, their slower-moving convectively coupled counterparts do not appear to have a substantial impact at this time scale.

\section{b. Impact of related idealized diabatic heat sources on the dry atmospheric dynamics}

We want to understand how diabatic heat sources located in the Indian sector may impact the convective activity in the African monsoon. In the preceding section we have extracted the filtered convectively coupled OLR signals of the MJO and Kelvin and equatorial Rossby waves to see how those modes contribute to the convective activity over Africa, seen in Fig. 2. We present now a set of simulations with a global dry primitive equation model forced with idealized Indian monsoon diabatic-heating fields, representing break and active phases of the Indian monsoon, to investigate the mechanisms of the associated atmospheric teleconnections.

\section{1) THE PRIMITIVE EQUATION MODEL}

The model and model setup used in this study is the same as that in Hall et al. (2006). We utilize a global spectral primitive equation model with horizontal resolution of T31 and 10 equally spaced sigma levels. A semi-implicit 22.5-min time step is used to integrate the full nonlinear equations for vorticity, divergence, temperature, and log (surface pressure). A basic state provided by NCEPI summer [June-September (JJAS)] climatology is kept fixed in the model by adding a forcing term that represents the combined effects of diabatic heating and transients. Perturbations about this basic state are constrained to be linear by imposing a very small forcing perturbation and subsequently rescaling the response for presentation. In addition, a 12-h $\nabla^{6}$ diffusion is applied to the momentum and temperature equations, and low-level damping is included to represent boundary layer processes. Average damping rates correspond to time scales of about 2 days for momentum and 4 days for temperature near the surface, following Hall and Sardeshmukh (1998) and Hall (2000). In the free atmosphere (above $\sigma=0.8$ ), damping time scales for momentum and temperature are around 30 and 10 days, respectively. For further details of the modeling setup see Hall et al. (2006).

\section{2) THE EXPERIMENT}

Four experiments have been performed to investigate the effects of different components of the diabatic heat source and their evolution over the Indian sector, as seen in Fig. 2, beginning at $t_{0}-20$. Each heat source is represented in the horizontal by an ellipse $20^{\circ}$ in longitude and $7^{\circ}$ in latitude. The heating rate has a cosine squared horizontal distribution and a vertical profile that follows $H_{0}=(\pi / 2) \sin \pi \sigma$ with a maximum at $500 \mathrm{hPa}$. The maximum vertical average heating (at the center of the anomaly) is $5 \mathrm{~K}$ day $^{-1}$. The heat source is switched on at the beginning of the integration and stays constant except in the case of the moving dipole (see below).

The four experiments are based on the distribution of the OLR anomalies at $t_{0}-20$ over the Indian sector as follows: 1) a negative heat source centered at $5^{\circ} \mathrm{S}, 80^{\circ} \mathrm{E}$; 2) a positive heat source centered at $20^{\circ} \mathrm{N}, 80^{\circ} \mathrm{E}$; 3) a combination of these two heat sources to form a constant dipole pattern; and 4) the same dipole pattern including a temporal evolution to simulate its northward displacement. This is achieved by oscillating between two quadrature phase patterns, the first being the dipole and the second a monopole at $7.5^{\circ} \mathrm{N}$, with a period of 40 days for a complete cycle. The experiment thus starts with a north-south heating-cooling dipole. By day 10 this is replaced with a central cooling 
monopole, and by day 20 the north-south dipole returns but with the sign reversed. Experiment 4 thus represents the northward propagation of a monsoon break, as seen in Fig. 2, between $t_{0}-20$ and $t_{0}$. The results for these four simulations are presented in Figs. 5-10. Geopotential height and wind at $850 \mathrm{hPa}$ are shown for evaluation of the low-level atmospheric circulation, to be compared with Fig. 2, and geopotential height at $250 \mathrm{hPa}$, temperature at $350 \mathrm{hPa}$, and vertical velocity at $650 \mathrm{hPa}$ are shown to evaluate the high-level signal and the associated midlevel forcing of vertical motion.

\section{3) The Results}

The response to the fixed negative diabatic heat source centered at $5^{\circ} \mathrm{S}, 80^{\circ} \mathrm{E}$ is presented in Fig. 5 through the evolution of the 250-hPa geopotential height and 650-hPa vertical velocity fields. In Fig. 5a, the location of the negative heat source can be seen by the maximum of downward vertical velocity at day 2 . The 850-hPa geopotential height fields are shown in Fig. 5 b. At mid and high levels (Fig. 5a) an equatorial dry Kelvin-Rossby wave pattern develops and extends in the tropical band but with very weak amplitude (see Fig. 5a caption for the amplitude range). This is similar to the patterns shown by Matthews (2004) with a similar speed, except that in this case the origin is not located over the Indonesian warm pool. The front of the dry Kelvin wave propagates rapidly eastward (see the spreading geopotential anomaly at $250 \mathrm{hPa}$ and the upward velocity pole at $650 \mathrm{hPa}$ over the eastern equatorial Pacific at day 4) and reaches Africa around one week after its initiation. On the other hand, the two anticyclonic poles of the Rossby wave move more slowly westward at $250 \mathrm{hPa}$. The northern one reaches Africa a bit earlier than the southern one, around 4 days after its initiation, and extends a bit more westward, primarily due to the asymmetry of the basic state. An extratropical Rossby wave train south of $20^{\circ} \mathrm{S}$ emanating from the longitude of the heat source also develops eastward along a circle path. At the $850-\mathrm{hPa}$ level the circulation pattern is not so well structured (Fig. 5b). No signal of the dry equatorial Kelvin wave appears along the equator either in geopotential or wind values. A positive equatorial Rossby wave signal develops in the wind field over the equatorial Indian basin and extends westward over Africa, but only east of $20^{\circ} \mathrm{E}$. The extratropical Rossby wave train south of $20^{\circ} \mathrm{S}$ appears to be strong and equivalent barotropic at 850 $\mathrm{hPa}$. In conclusion, whereas the equatorial KelvinRossby wave pattern is well defined at mid and high levels, it does not induce strong modulation of the lowlevel circulation in the West African monsoon in this dry simulation.
Figure 6 shows the response to the fixed positive diabatic heat source centered at $20^{\circ} \mathrm{N}, 80^{\circ} \mathrm{E}$. The $250-\mathrm{hPa}$ geopotential height pattern associated with the equatorial dry Kelvin-Rossby wave pattern develops and extends in the tropical band (Fig. 6a). It is similar to the preceding one except that its sign is opposite and the signal of the Kelvin wave is weaker and the equatorial Rossby wave stronger, consistent with the higher latitude of the heat source. Again, the front of the Kelvin wave propagates rapidly eastward and reaches Africa around one week after its initiation, whereas the two cyclonic poles of the equatorial Rossby wave move more slowly westward but reach West Africa around 3 days after their initiation. A very weak signal from the induced Kelvin vertical velocity is present along the equator (Fig. 6a). At $850 \mathrm{hPa}$ no signal of the Kelvin wave emerges in the geopotential height and wind fields (Fig. 6b). On the other hand, at day 2 the quadrupole located around the heat source is characteristic of Rossby response, as shown by Gill (1980). In the five following days the negative geopotential height pole propagates southwestwards to reach northeastern Africa and then extends westward over the Sahel and northern Africa. The circulation pattern exhibits increased low-level westerly winds, which would increase moisture advection within the ITCZ, favoring enhanced convection over West Africa. In the 650-hPa vertical velocity field sequence (Fig. 6a) from day 4 to 10 , we can see a subsiding area over North Africa, consistent with the simulations of Rodwell and Hoskins (1996), and weak upward vertical velocity over the Sahel. So, the Rossby response not only puts in place a circulation anomaly that would enhance moisture advection but also directly forces upward motion in the location of the African ITCZ. Both of these effects would tend to enhance precipitation in the region. This westward propagating signal is evident over Africa, in Fig. 2, from $t_{0}-20$, with similar geopotential height and wind amplitudes, and contributes to the dissipation of the positive OLR anomalies between $t_{0}-20$ and $t_{0}-15$. It can also explain the east-to-west initiation and development of negative OLR anomalies seen from $t_{0}-10$, in Fig. 2 . Figure 6 also shows that the northern heat source excites a wave structure that propagates eastward through the Asian jet and out into the Pacific. This is a growing baroclinic wave as evidenced by the westward tilt with height, and it will also be a feature of the dipole solutions shown below. However, since this region is evidently unstable for the current combination of basic state and damping, this part of the solution may be sensitive to other extratropical sources and is therefore difficult to interpret as being clearly associated with the Indian monsoon forcing. 
(a)

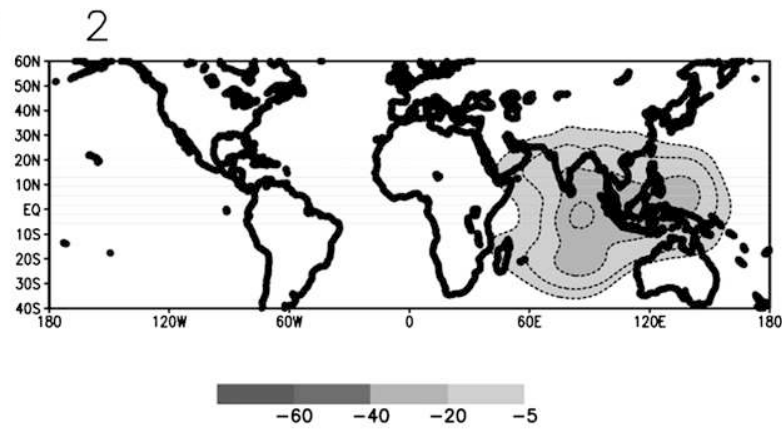

4

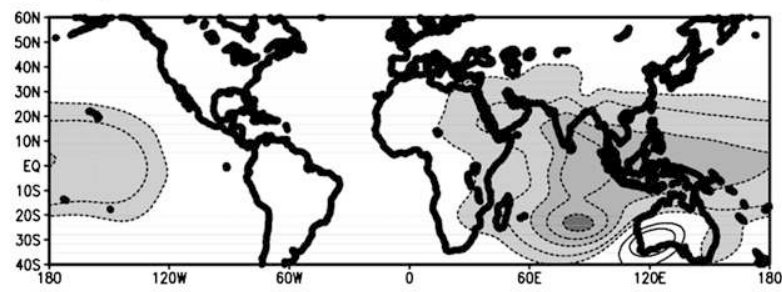

6

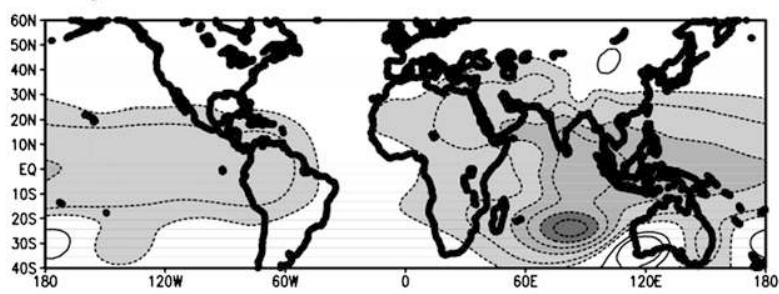

8

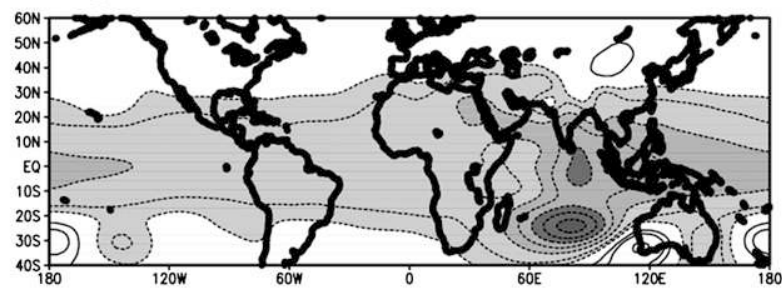

10

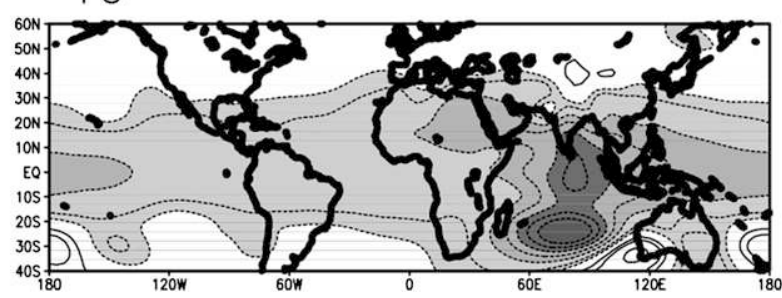

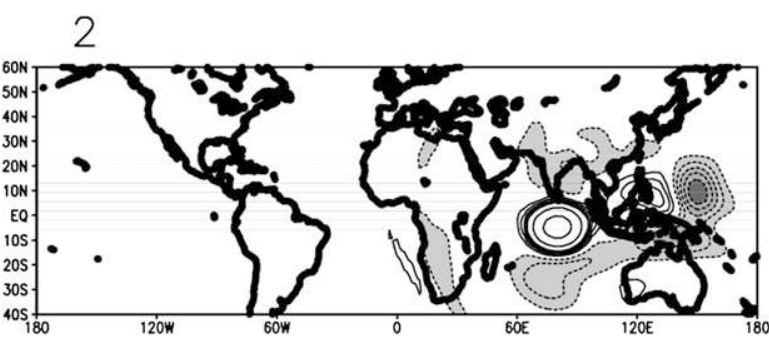

4

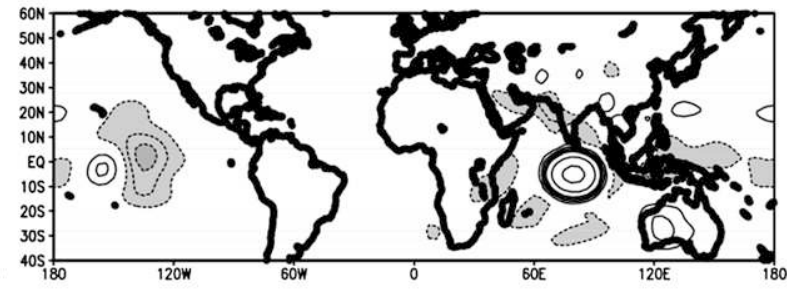

6

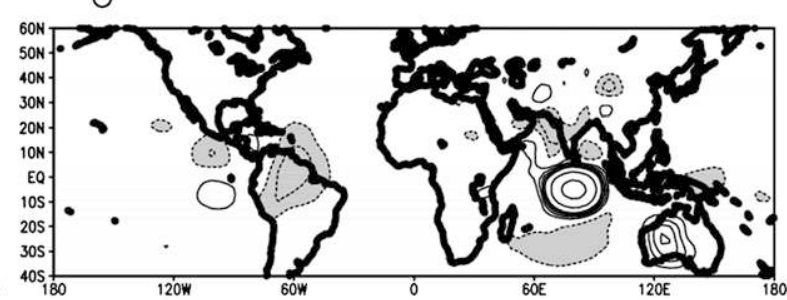

8

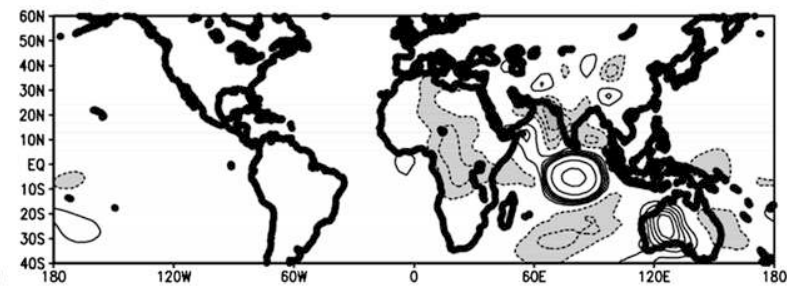

10

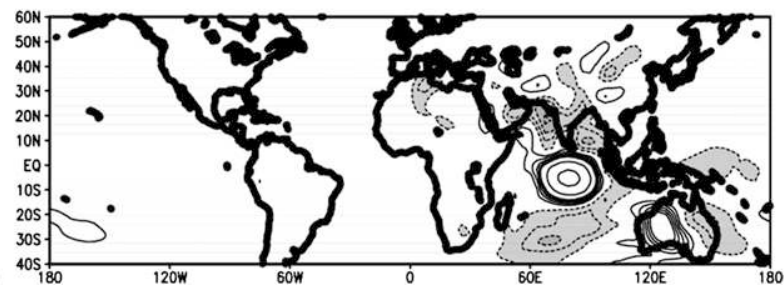

FIG. 5. Simulation with a diabatic heat source centered at $5^{\circ} \mathrm{S}, 80^{\circ} \mathrm{E}$ : (a) (left) Geopotential height (gpm) at $250 \mathrm{hPa}$ (isolines \pm 5 , \pm 10 , $\pm 20, \pm 30, \pm 40, \pm 50, \pm 60, \pm 80, \pm 100$; shaded negative values) and (right) vertical velocity (hPa s${ }^{-1}$ ) at $650 \mathrm{hPa}$ (isolines $\pm 0.2, \pm 0.4, \pm 0.6$, $\pm 0.8, \pm 1, \pm 2, \pm 4, \pm 6$; upward motion for shaded negative values) for days $2,4,6,8,10$. (b) Geopotential height at $850 \mathrm{hPa}$ (isolines $\pm 2, \pm 4$, $\pm 6, \pm 8, \pm 10, \pm 20, \pm 40, \pm 60$; shaded positive values) and wind at $850 \mathrm{hPa}$ (vector; $\mathrm{m} \mathrm{s}^{-1}$ ) for days 2 to 20 with a 2 -day lag. For better clarity, wind vectors greater than $5 \mathrm{~m} \mathrm{~s}^{-1}$ have been displayed with a $5 \mathrm{~m} \mathrm{~s}^{-1}$ length, and only one vector out of every two is displayed.

Figure 7 shows the response to the fixed diabatic heat source dipole combining the two preceding heat sources. As the experiments are linear, the response for a fixed dipole is the sum of the two previous experiments. At
$250 \mathrm{hPa}$ the Rossby wave contribution from the northern pole dominates over Africa, and in the Southern Hemisphere the combined response produces an east-west dipole. At $650 \mathrm{hPa}$ upward vertical velocity extends 
(b)
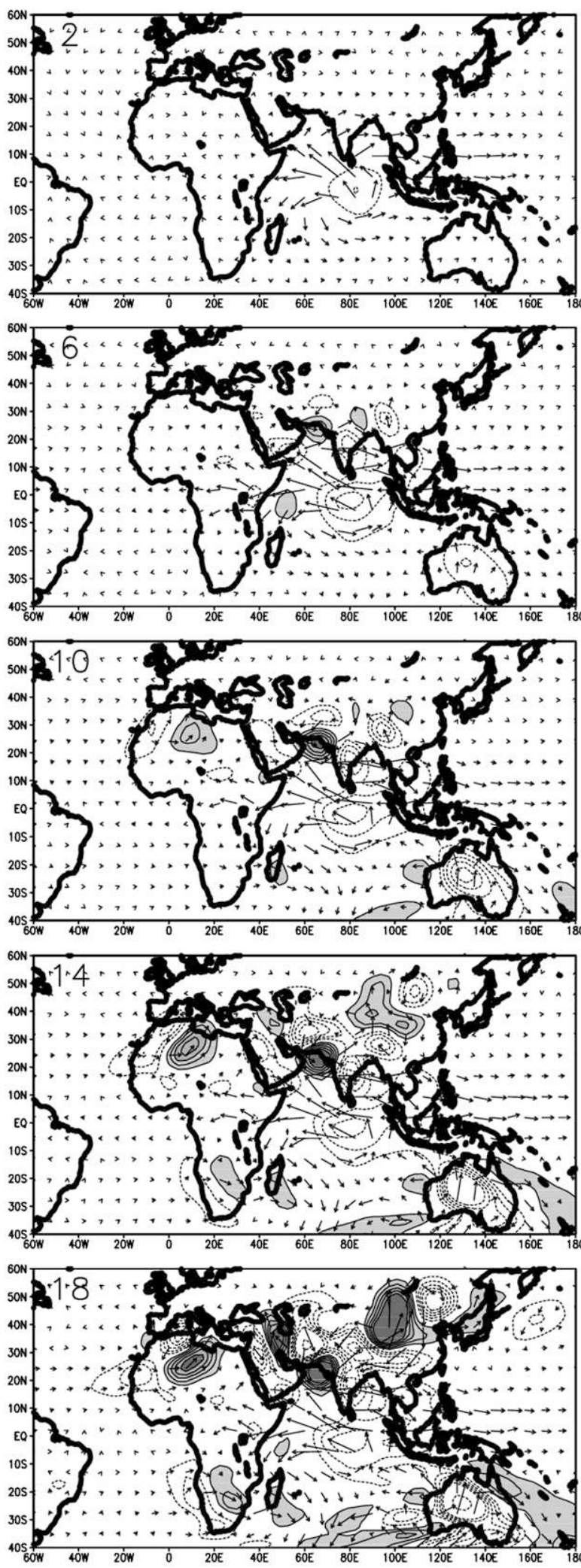
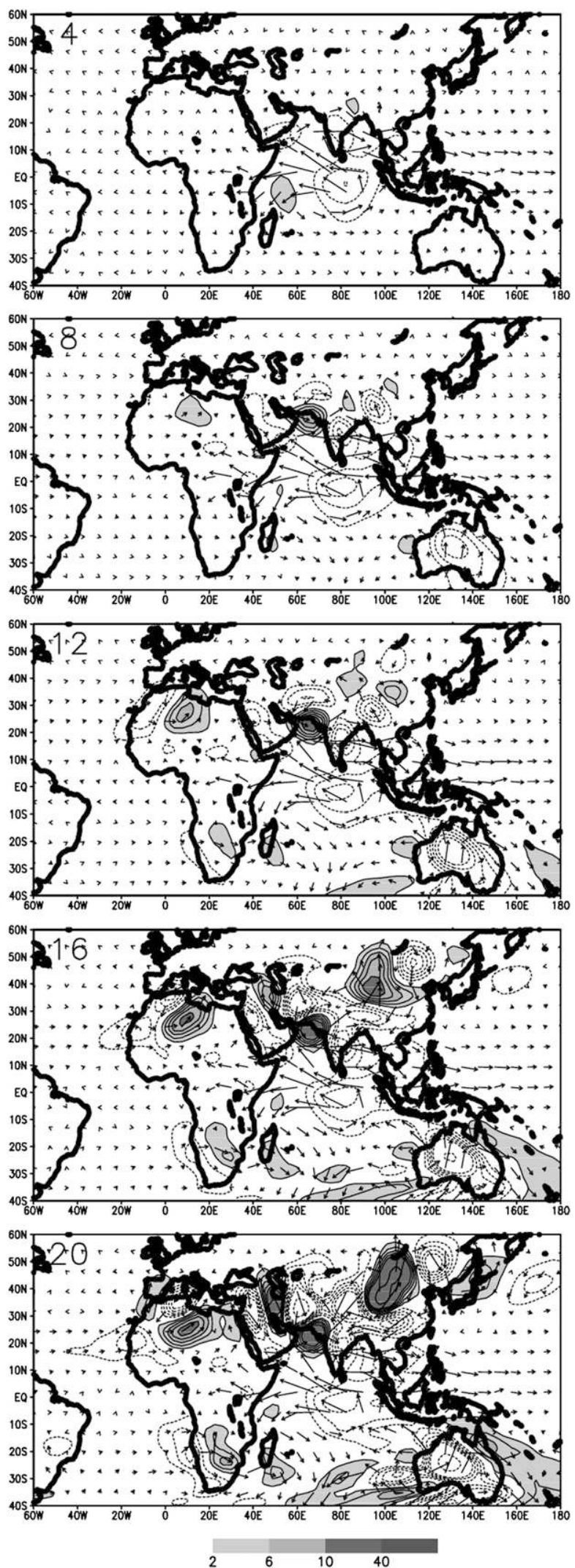

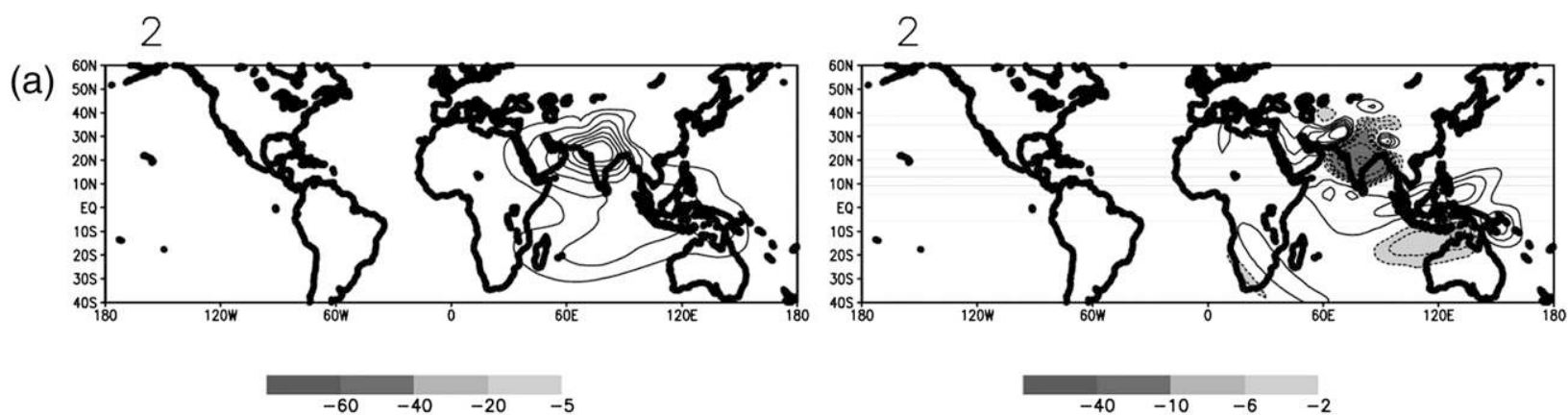

\section{4}

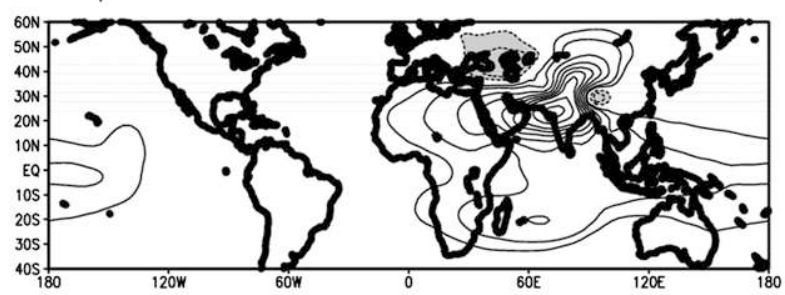

6

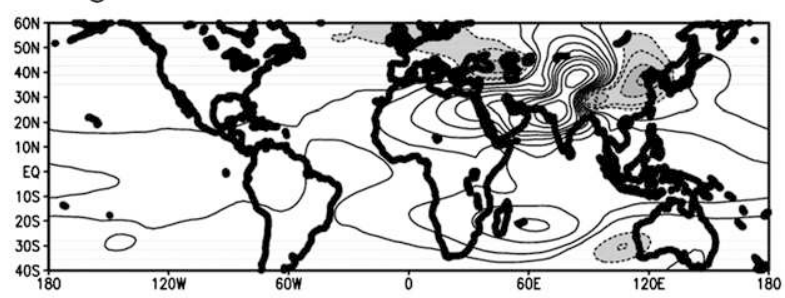

8

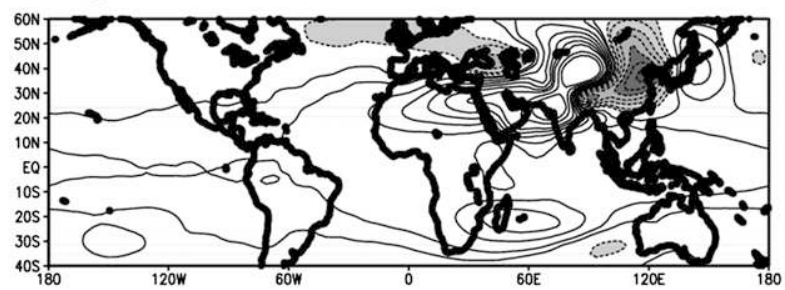

10

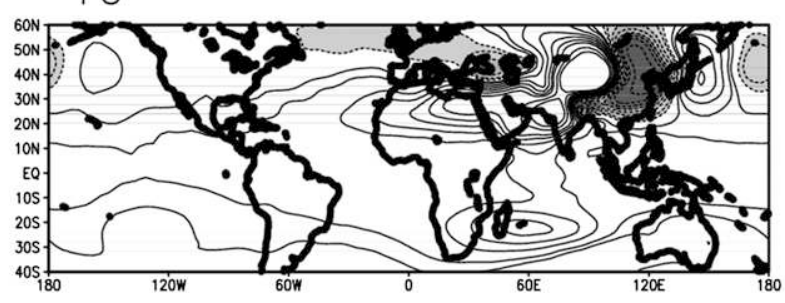

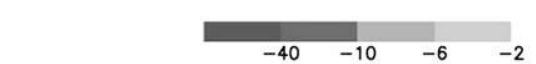

4

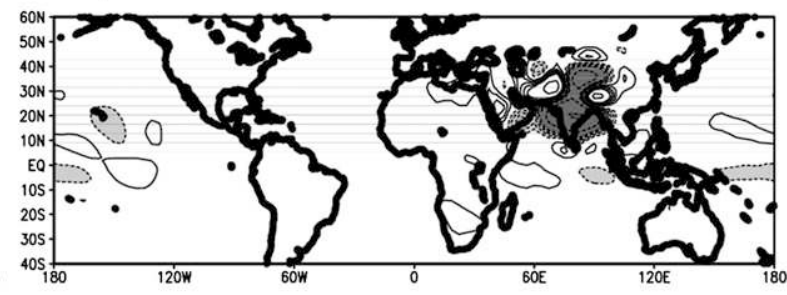

6

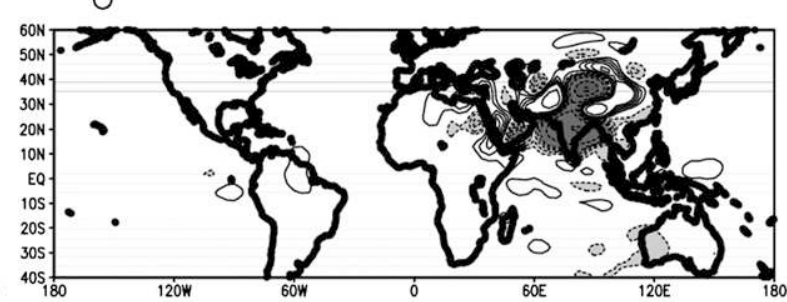

8

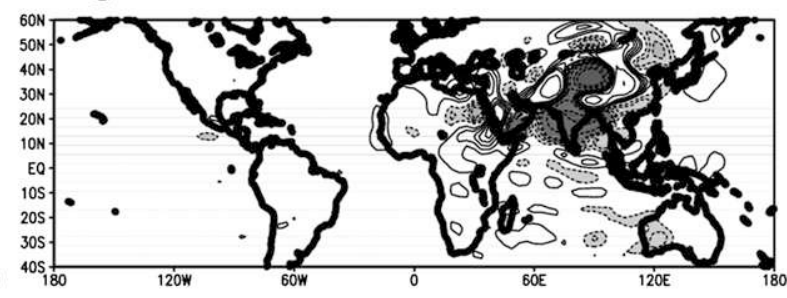

10

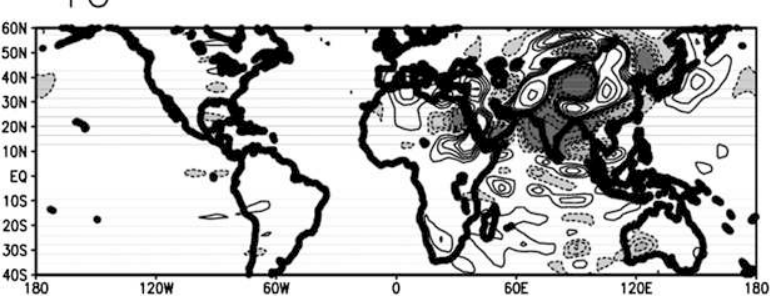

FIG. 6. As in Fig. 5 but for the diabatic heat source centered at $20^{\circ} \mathrm{N}, 80^{\circ} \mathrm{E}$.

westward over the eastern Sahel, as in Fig. 6a, but with a higher amplitude. This signal reaches its highest value at day 8 with a horseshoe pattern associated with the dry equatorial Rossby wave. The Kelvin response is attenuated by cancellation but the timing is not changed. At $850 \mathrm{hPa}$ only the geopotential height induced by the northern diabatic heat source modulates the low-level circulation over West Africa. This leads again to the slow westward development of low-level cyclonic circulations over northern Africa and enhanced westerly winds over the Sahel, potentially feeding moisture advection inland and deep convection in the ITCZ. The meridional dipole of convective heating present in the Indian sector thus excites a dry Kelvin-Rossby wave pattern dominated by 
(b)
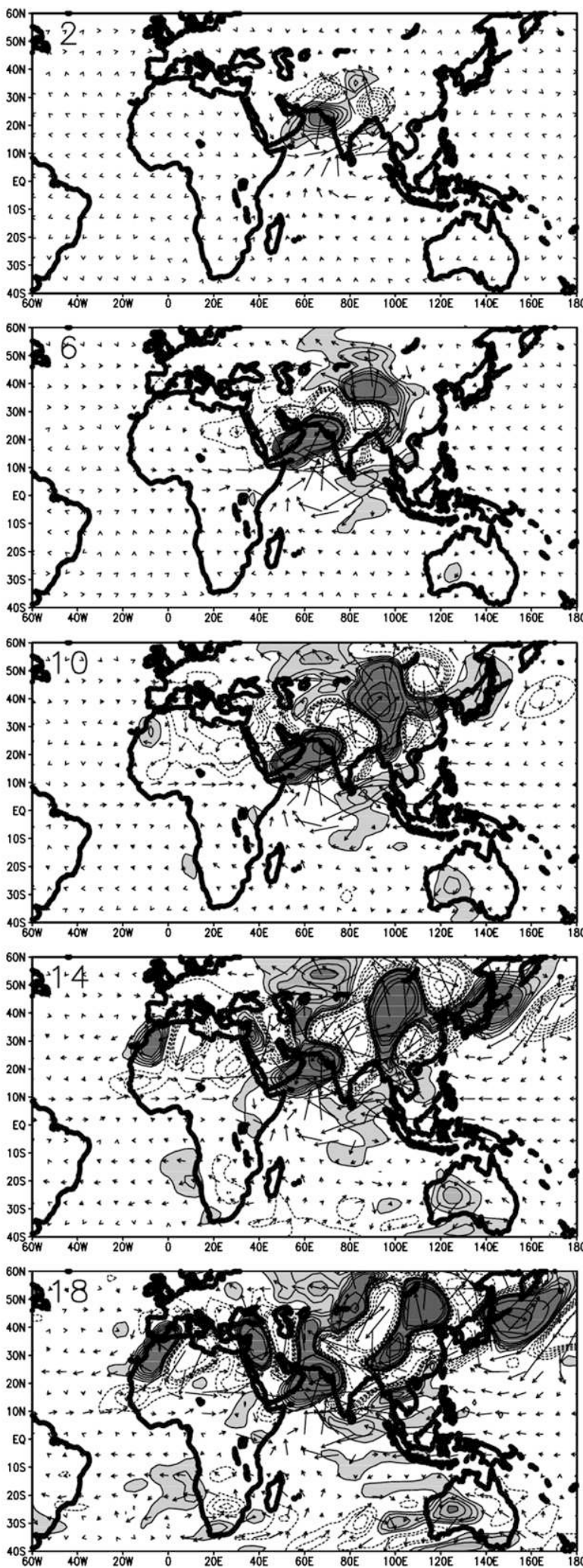
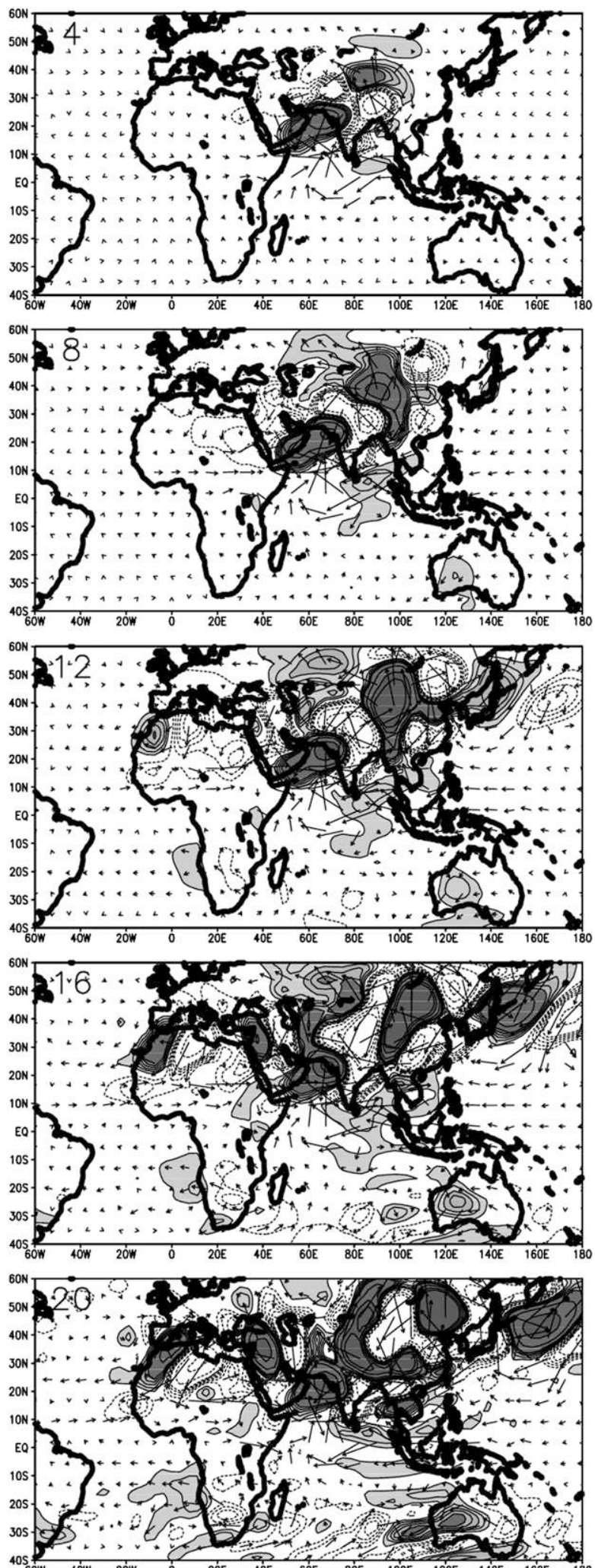

FIG. 6. (Continued) 
(a)

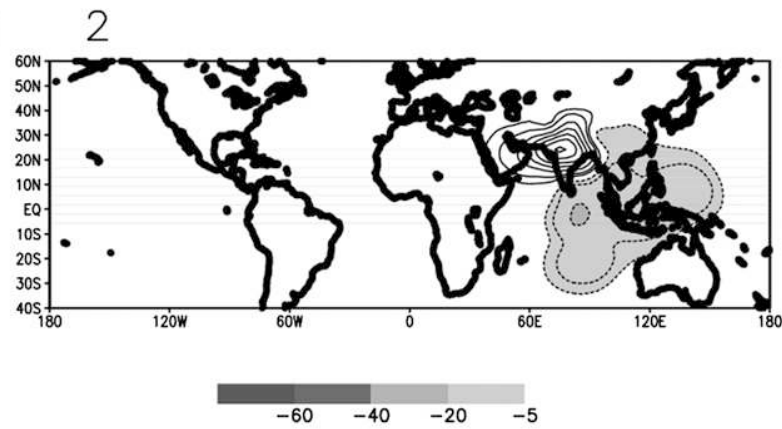

4

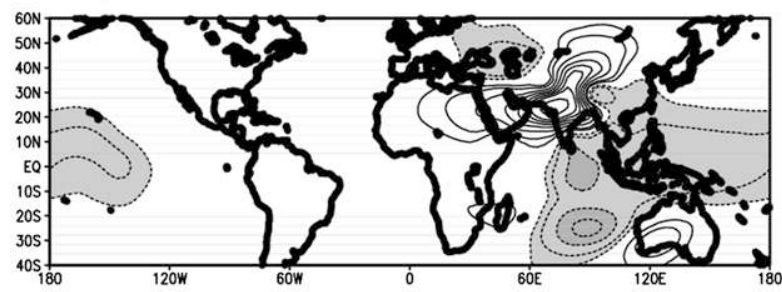

6

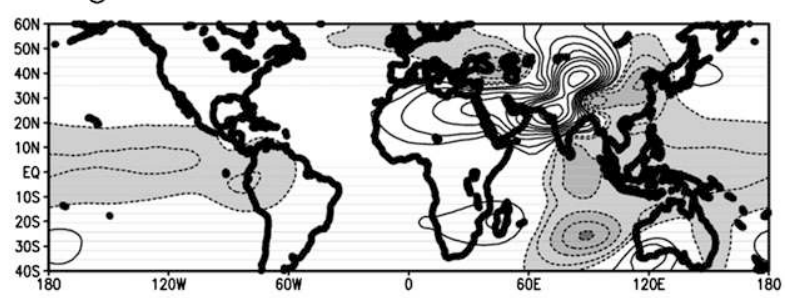

8

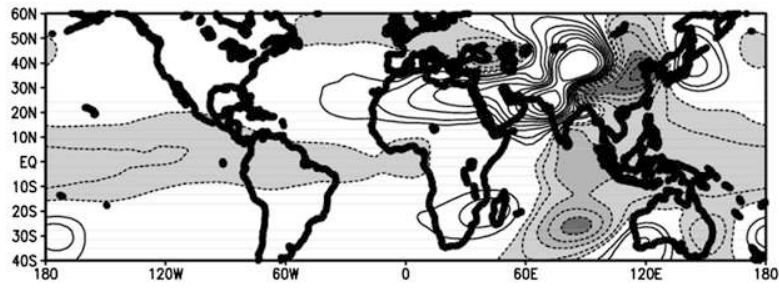

10

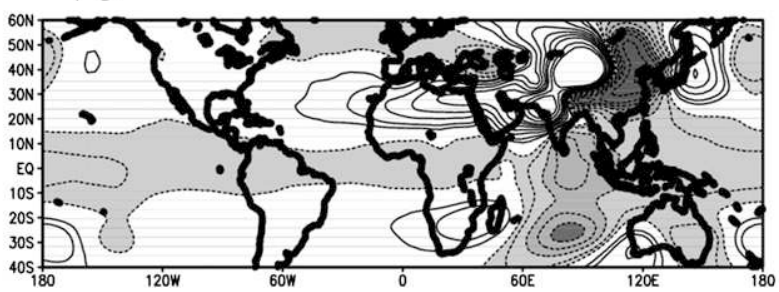

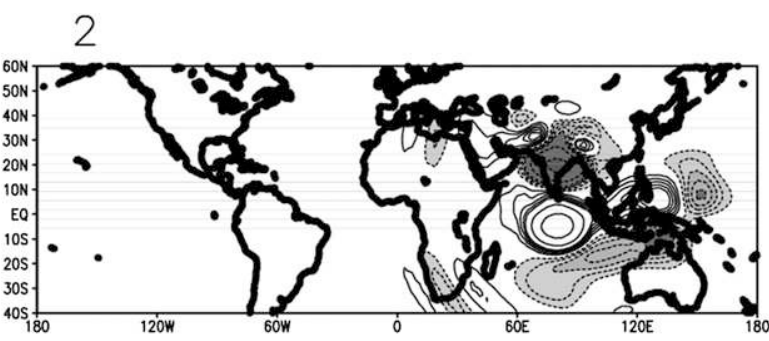

4

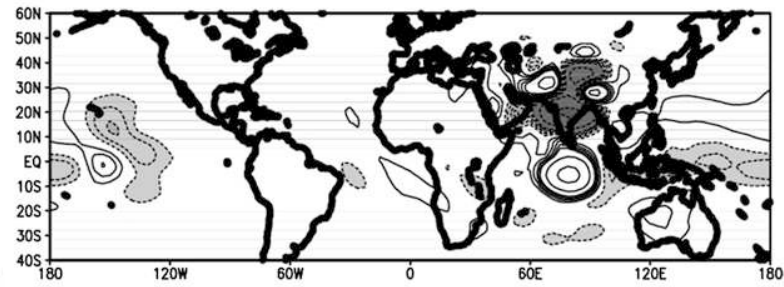

6

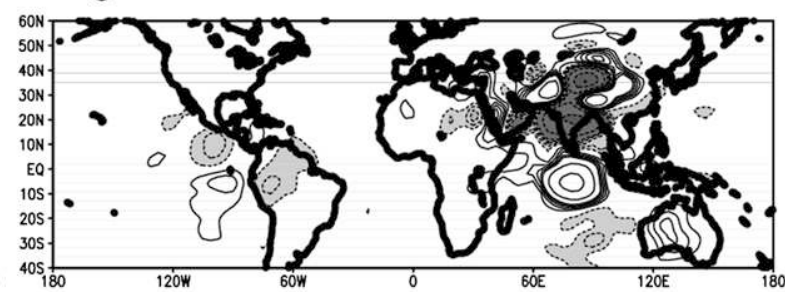

8

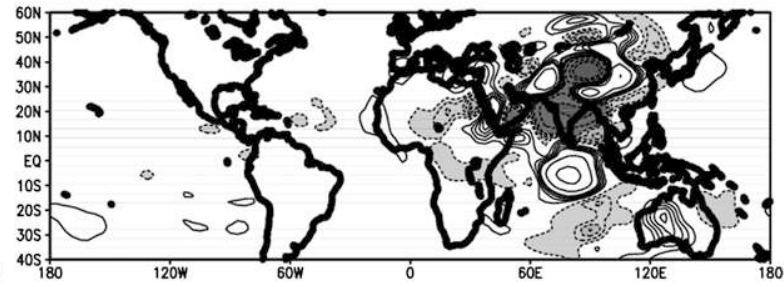

10

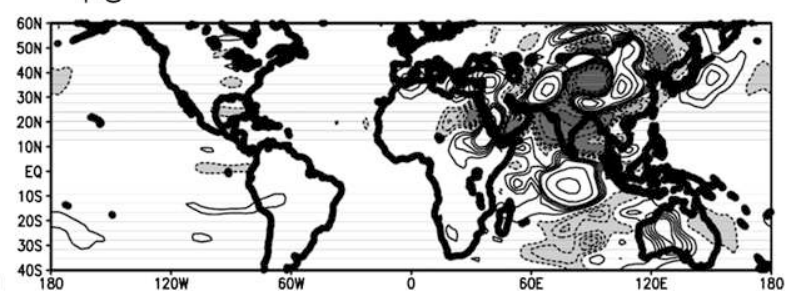

FIG. 7. As in Fig. 5 but for a constant dipole diabatic heat source.

the Rossby response and favorable to deep convective activity over Africa. This scenario is a bit different from the one shown in Matthews (2004).

Finally, by introducing a northward movement inside the dipole structure, Fig. 8 shows the response to the moving diabatic heat source dipole that simulates the northward propagation of a break phase in the Indian monsoon, as seen in Fig. 2. There are two main consequences of imposing this northward shift.

First, at high levels (Fig. 8a) it reduces the southern part of the Rossby wave pattern over Africa as the northern heat source gradually diminishes during the integration. Neither the weak Kelvin wave front progressing eastward nor the upward motion over Africa 
(b)
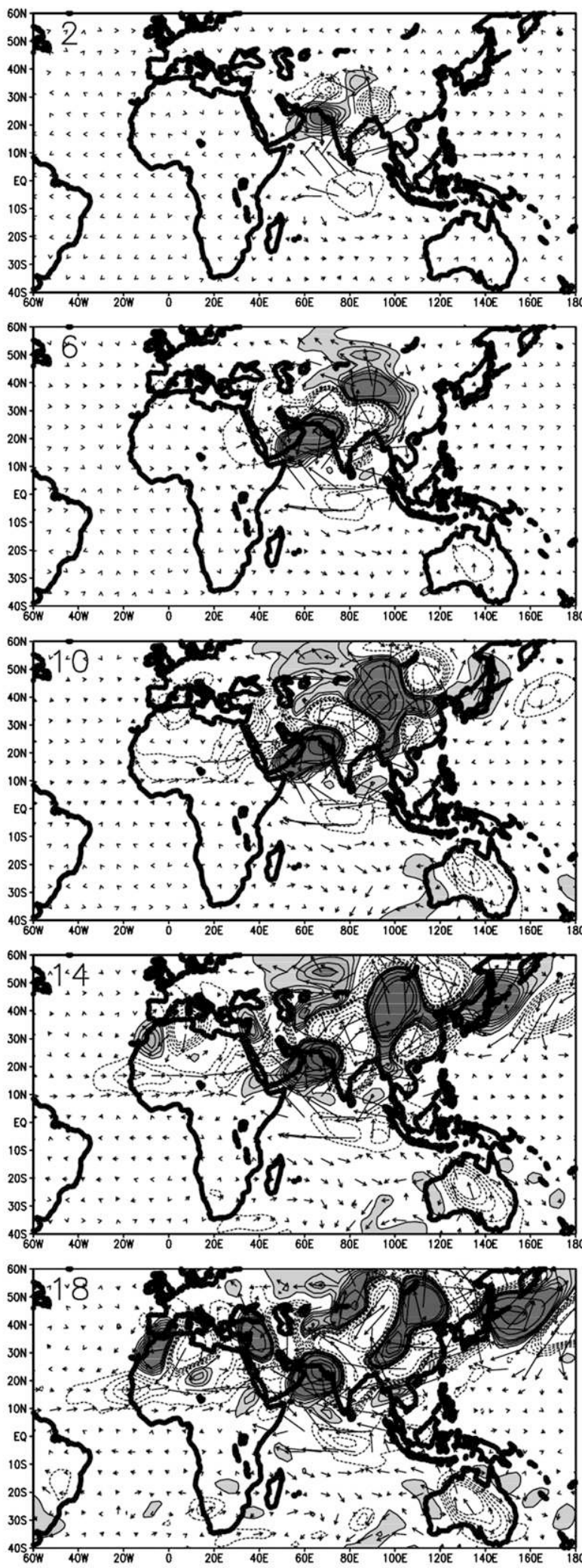
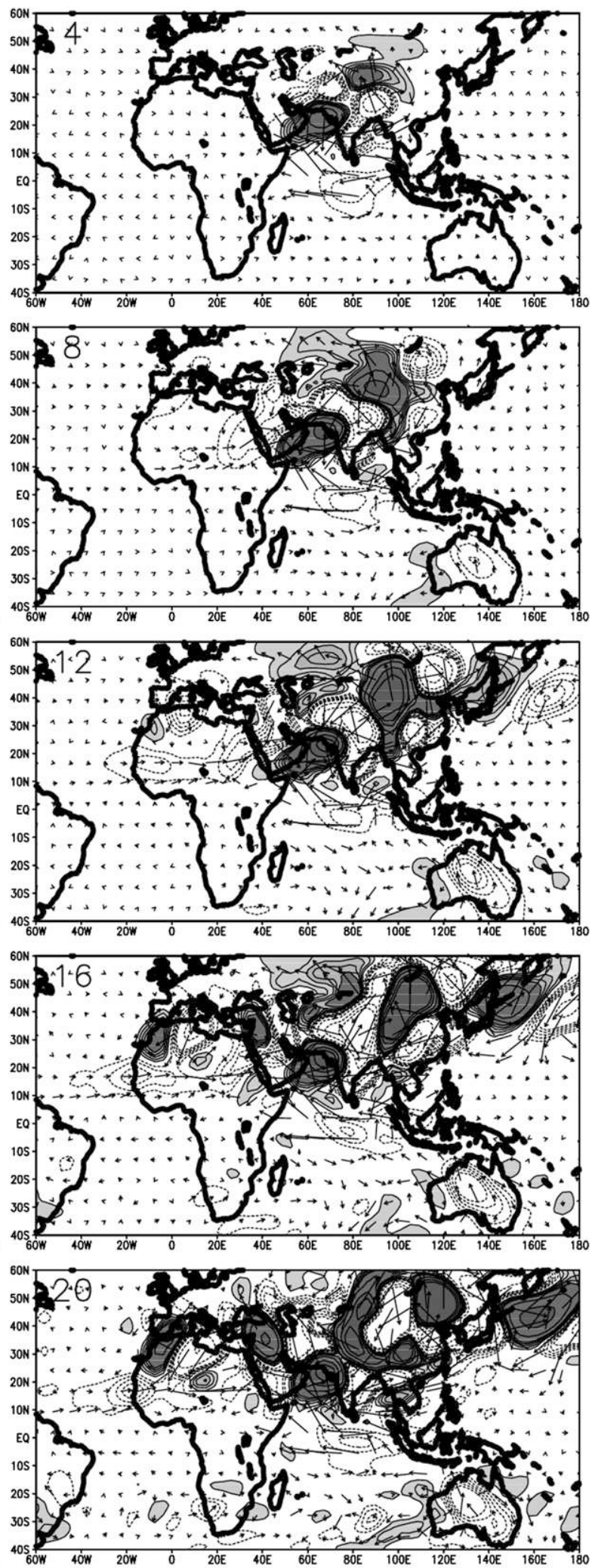

FIG. 7. (Continued) 
(a)

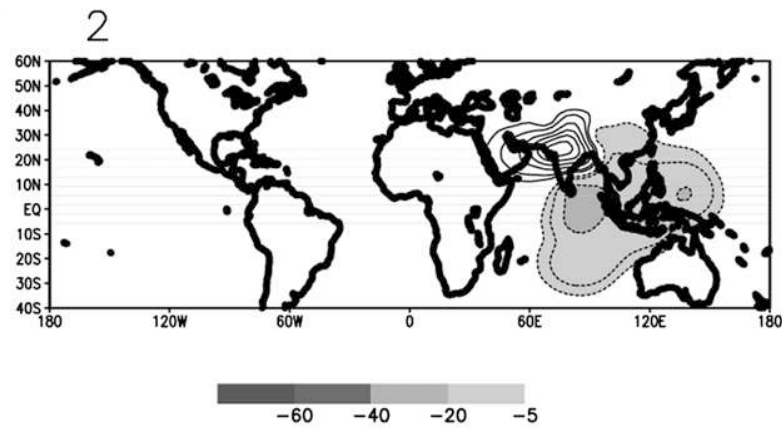

4

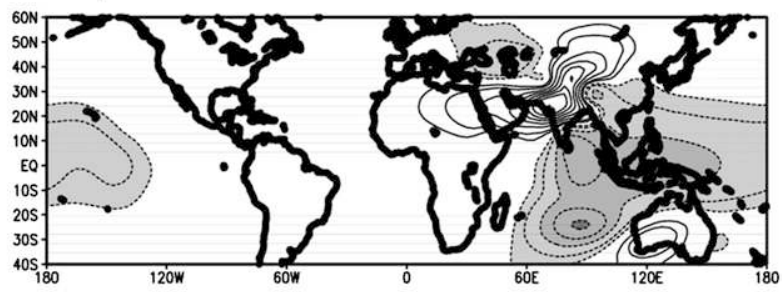

6

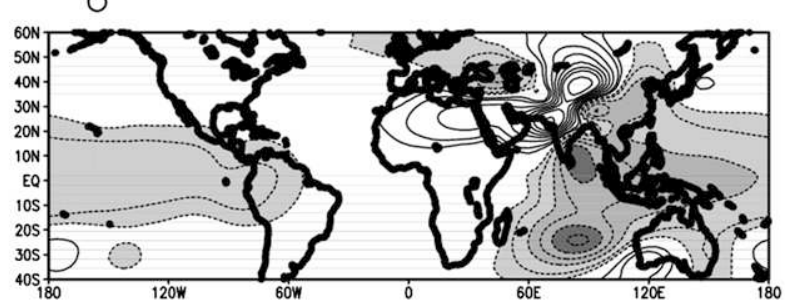

8

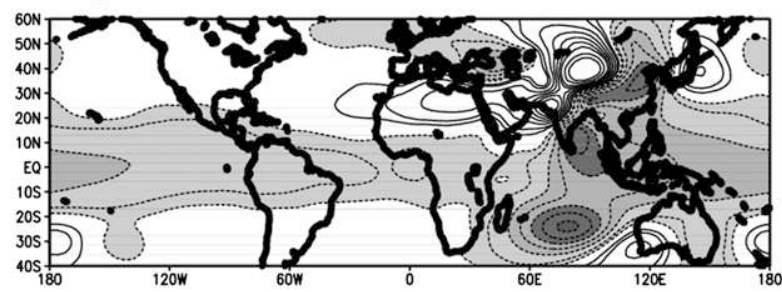

10

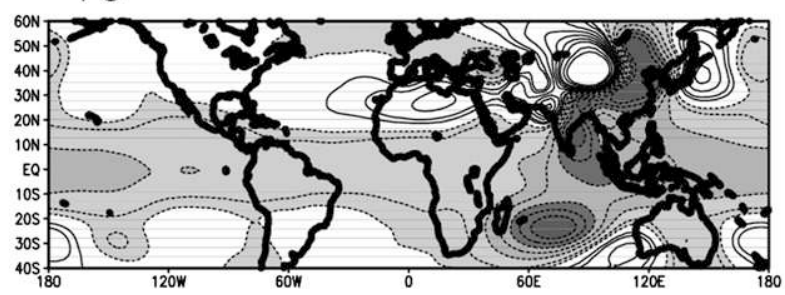

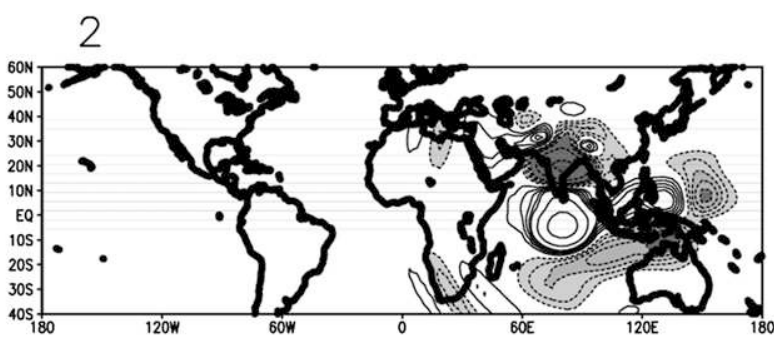

4

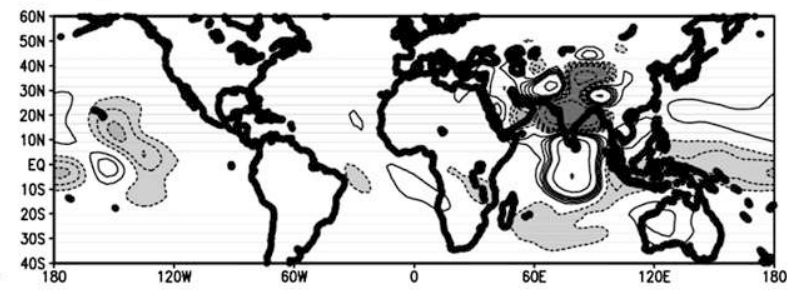

6

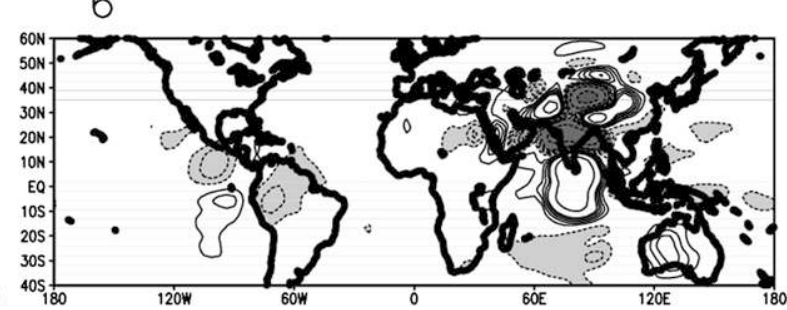

8

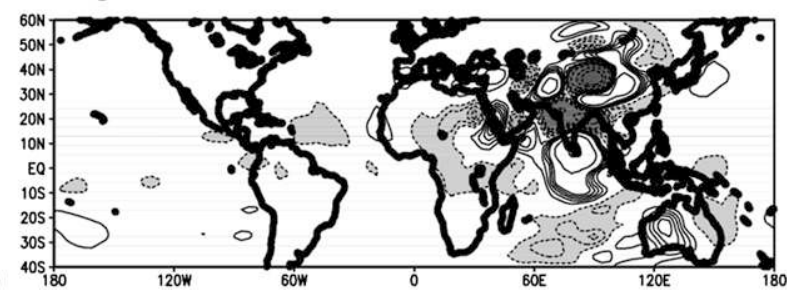

10

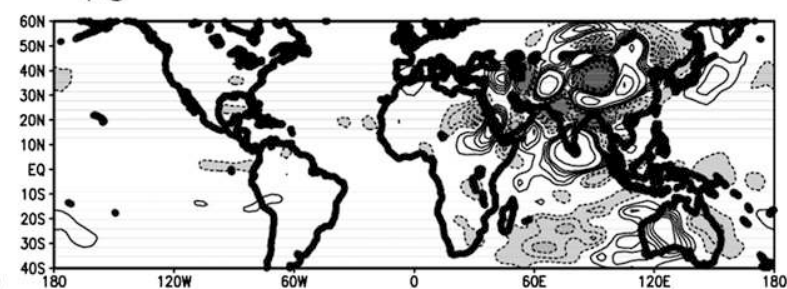

FIG. 8. As in Fig. 5 but for the moving dipole diabatic heat source.

are significantly modified except for a slight enhancement of the horseshoe upward velocity pattern present east of $0^{\circ}$ at day 8 . Figure 9 compares the averaged $10^{\circ} \mathrm{S}-15^{\circ} \mathrm{N} 350$-hPa temperature and $250-\mathrm{hPa}$ geopotential height longitude-time sequence of the moving dipole simulation and the composite unfiltered NCEP data sequence. To ensure that the diabatic heating in the
Indian sector coincides with the model runs from day 1 to day 19, we compare it with the composite NCEP sequence from $t_{0}-15$ to $t_{0}+3$. We must also note that the initial states are different in the simulation and in the NCEP sequences as the model starts from an undisturbed state, whereas at $t_{0}-15$ the NCEP fields are influenced by the preceding phase of the Indian 
(b)
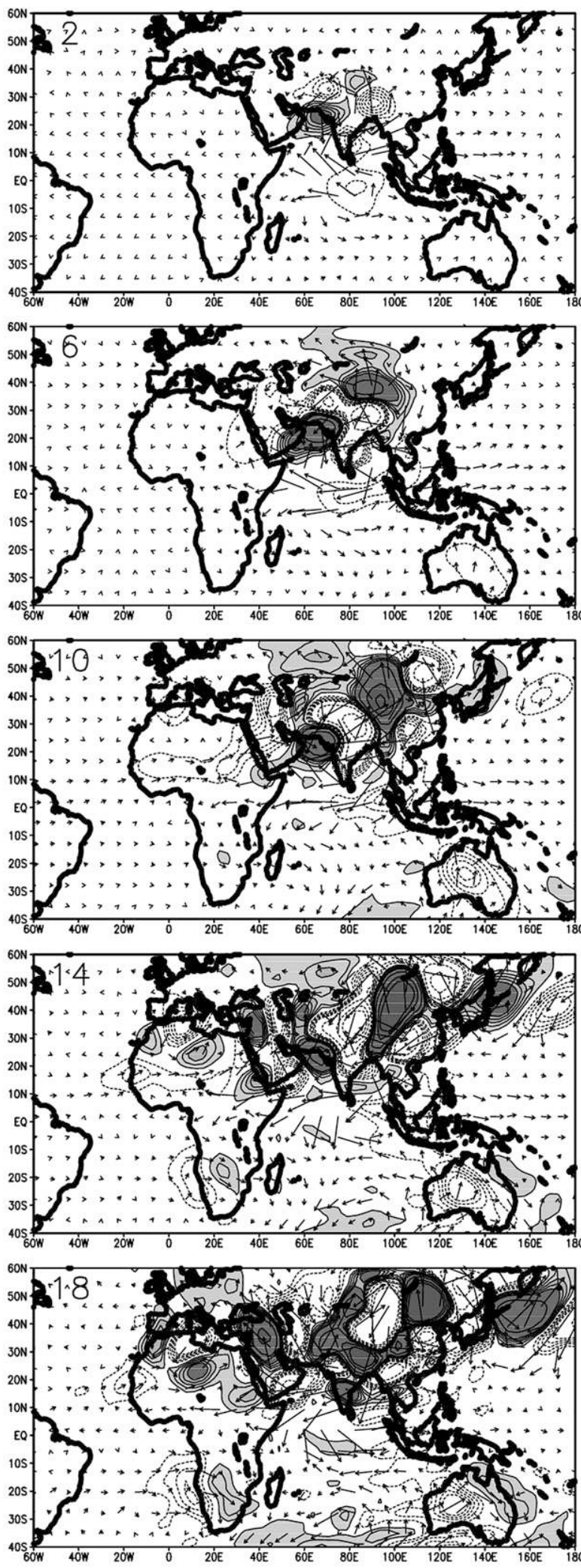
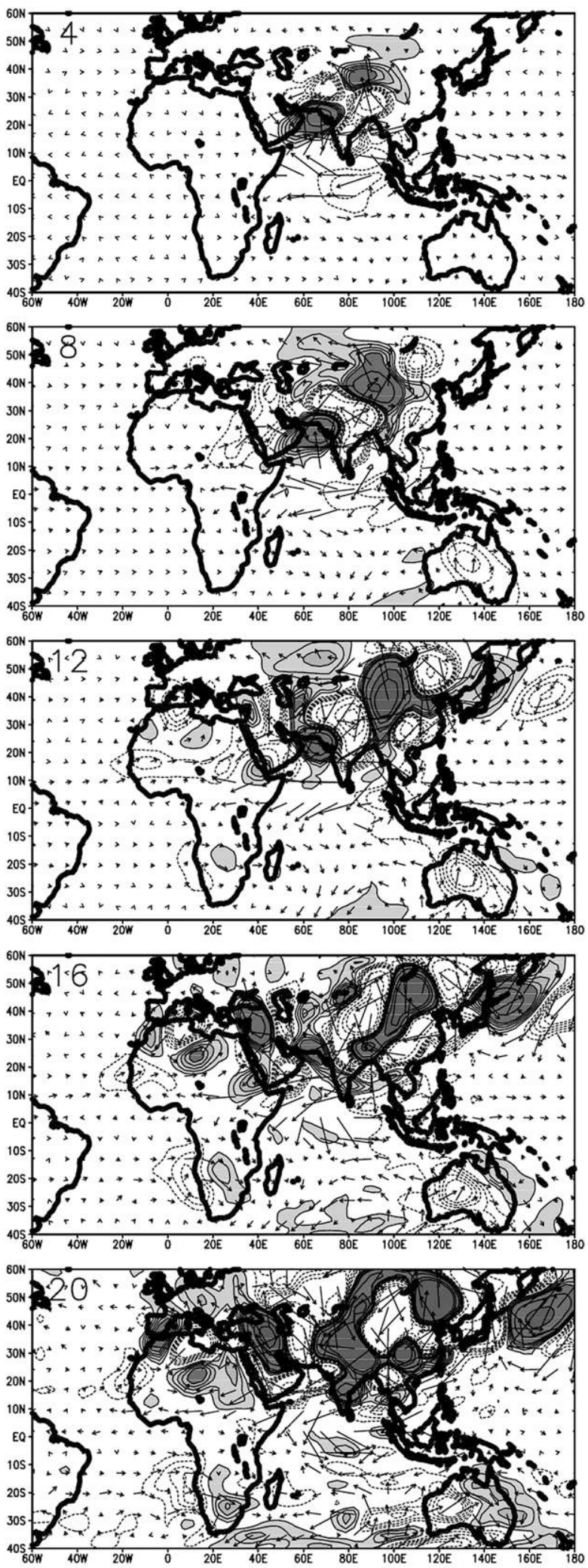

FIG. 8. (Continued) 
T350hPa Model 10S-15N day $1 /$ day 19
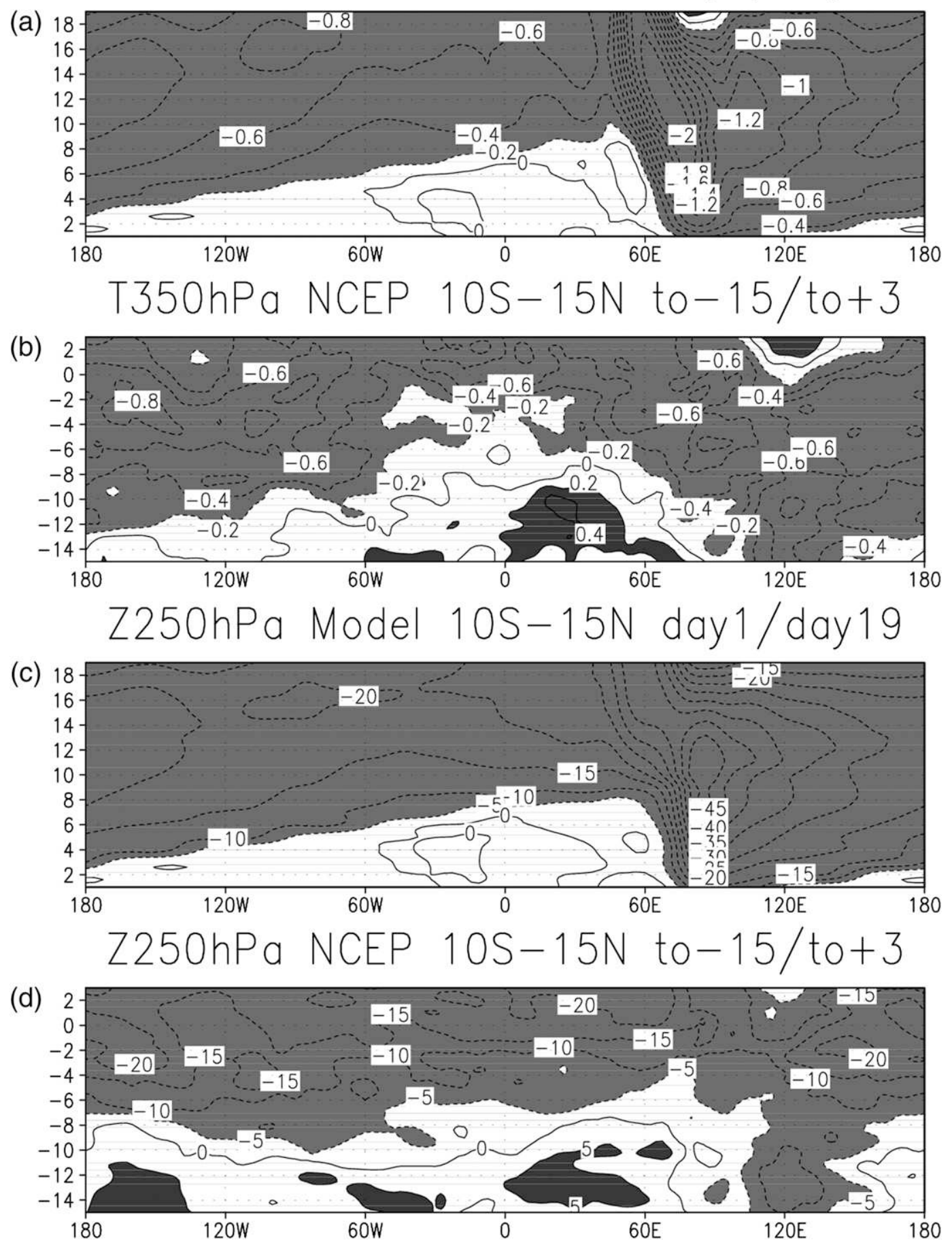

FIG. 9. Time-longitude diagrams averaged over $10^{\circ} \mathrm{S}-15^{\circ} \mathrm{N}$ of (a) moving-dipole simulation of 350 -hPa temperature $\left({ }^{\circ} \mathrm{C}\right)$ sequence from day 1 to day 19 and (b) composite unfiltered 350-hPa NCEP temperature $\left({ }^{\circ} \mathrm{C}\right)$ sequence from $t_{0}-15$ to $t_{0}+3$. (c) As in (a) but for 250-hPa geopotential height (gpm); (d) as in (b) but for 250-hPa unfiltered NCEP geopotential height. 
(a)

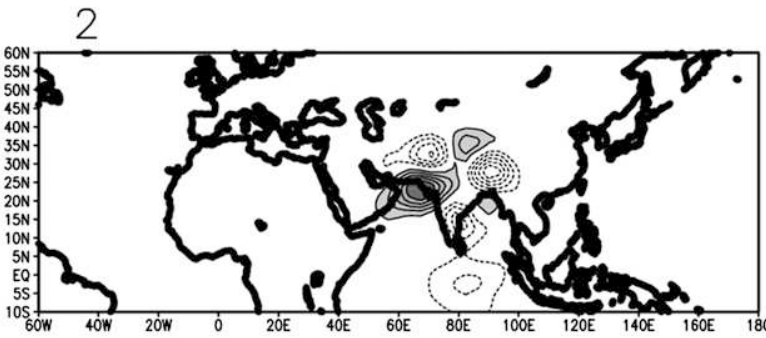

6

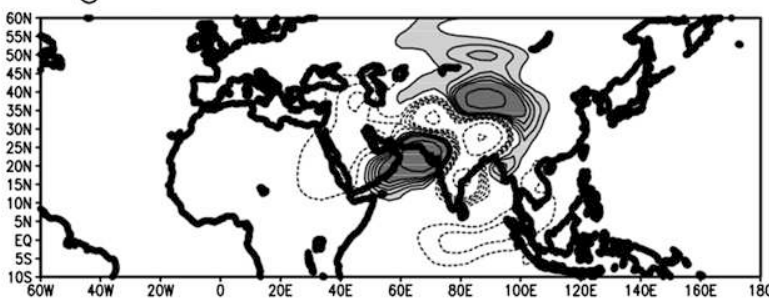

10
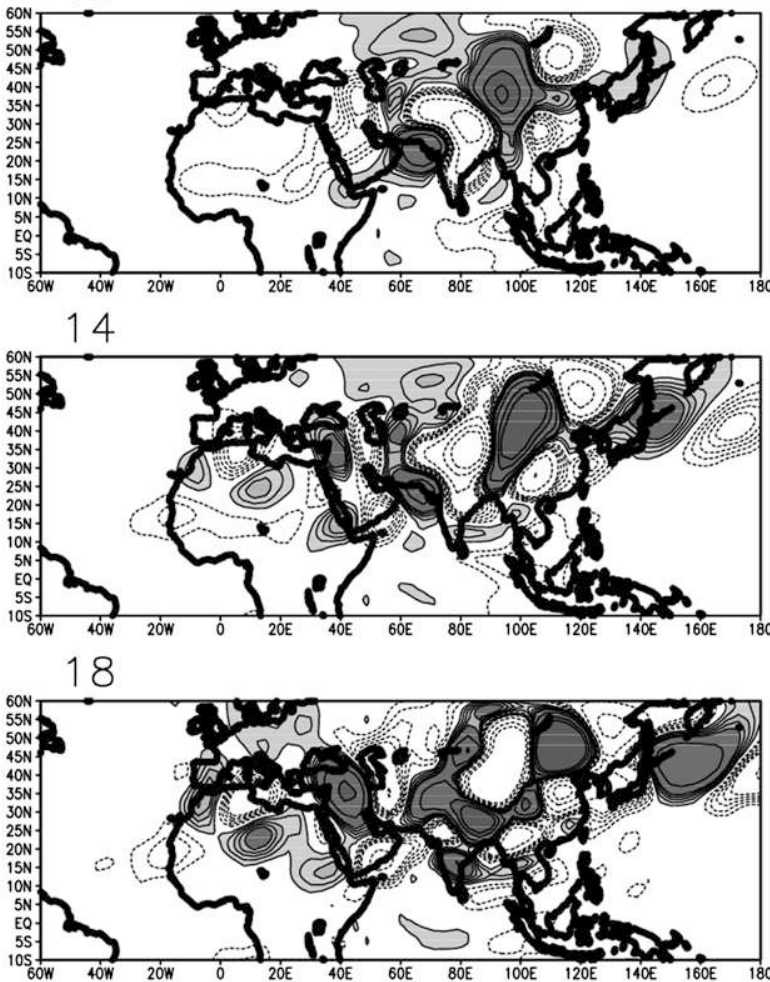

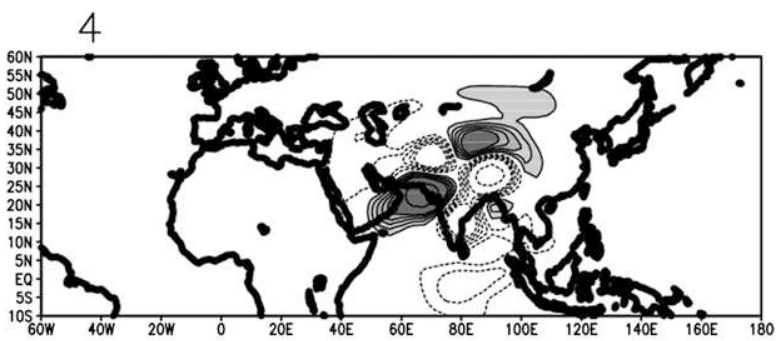

8

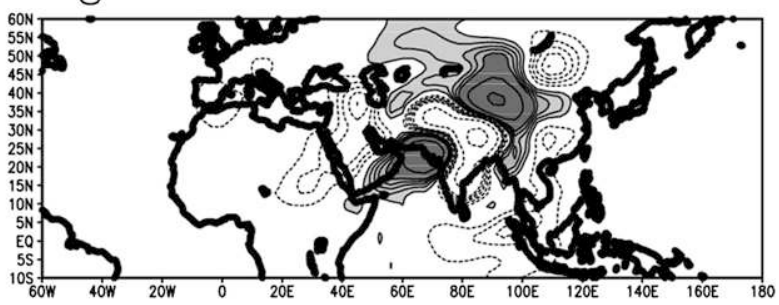

12

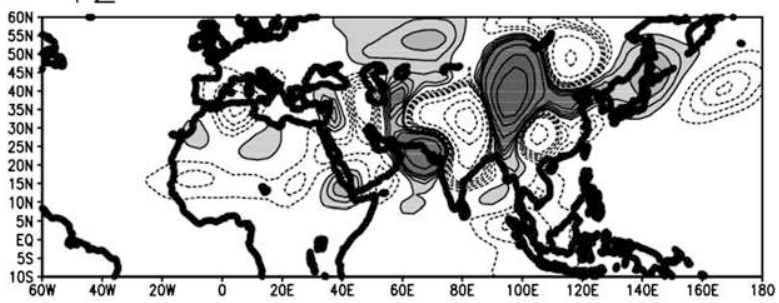

16

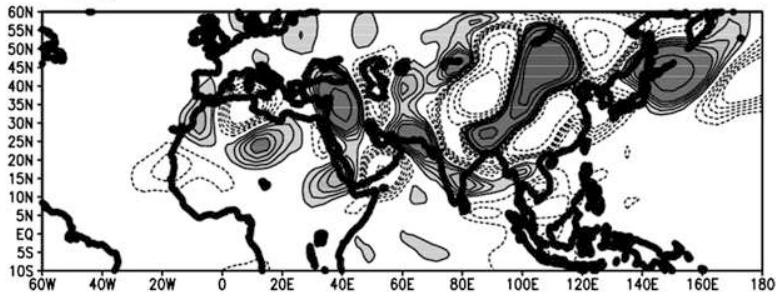

20

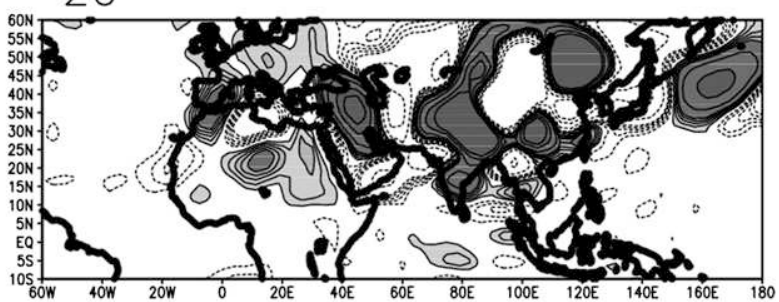

$2 \quad 6 \quad 10 \quad 40$

FIG. 10. Geopotential height (gpm) at $850 \mathrm{hPa}$ (isolines $\pm 2, \pm 4, \pm 6, \pm 8, \pm 10, \pm 20, \pm 40, \pm 60$; shaded positive values) (a) for the simulation with the moving dipole diabatic heat source for days 2 to 20 with a 2-day lag (this is similar to Fig. 8 b but on a reduced latitude domain) and (b) for the composite unfiltered NCEP data time sequence from $t_{0}-14$ to $t_{0}+4$ days with a 2-day lag.

monsoon. However, these fields appear similar in their evolution. The simulation shows the rapid eastward propagation of the negative Kelvin wave, the slow westward extension of the negative equatorial Rossby wave, and their meeting at $\sim 45^{\circ} \mathrm{E}$. In the composite
NCEP sequence, the starting longitude is different (around $120^{\circ} \mathrm{E}$ ) owing to the different diabatic heat source pattern at the equator, the Kelvin signal moves slower, and the Rossby signal extends more to the west. This may be due to the dry dynamics in the model, 
(b)
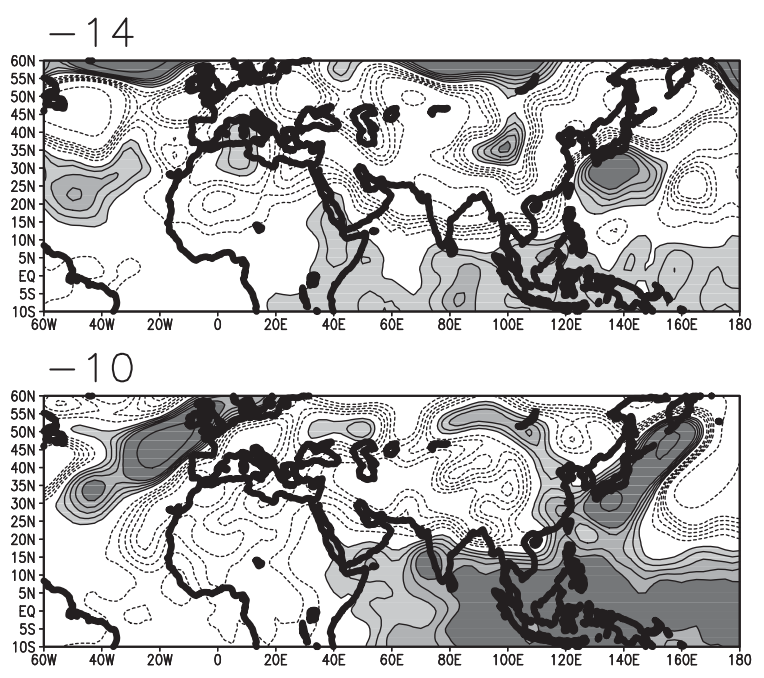

$-6$
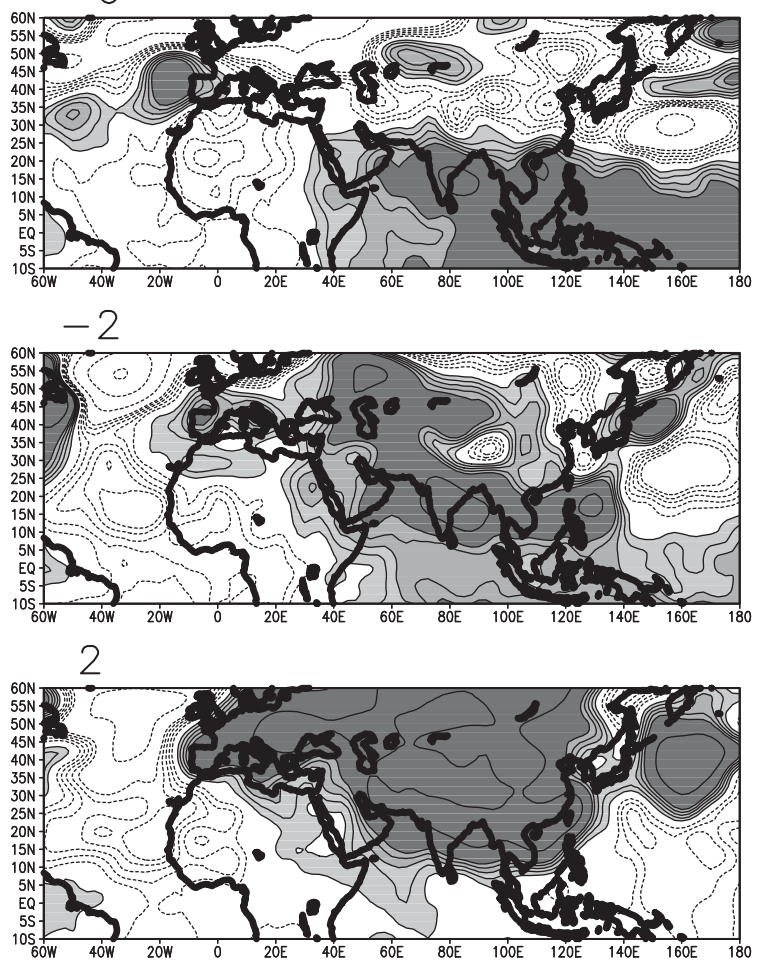

$-12$

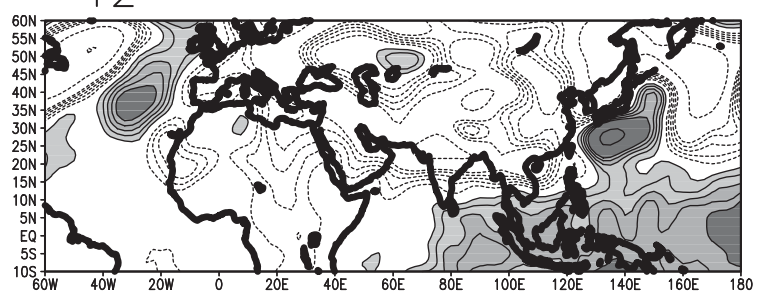

$-8$

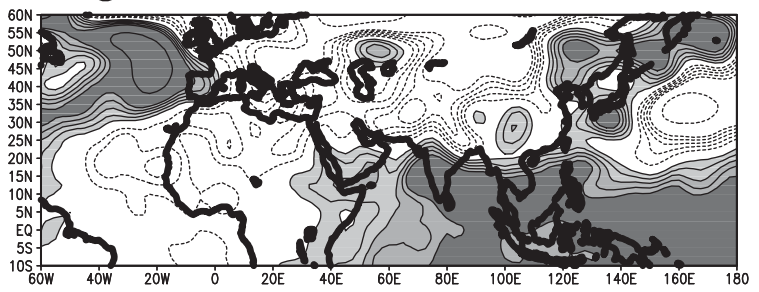

$-4$

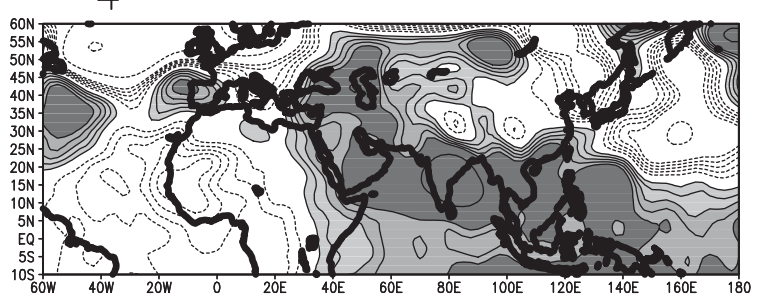

0

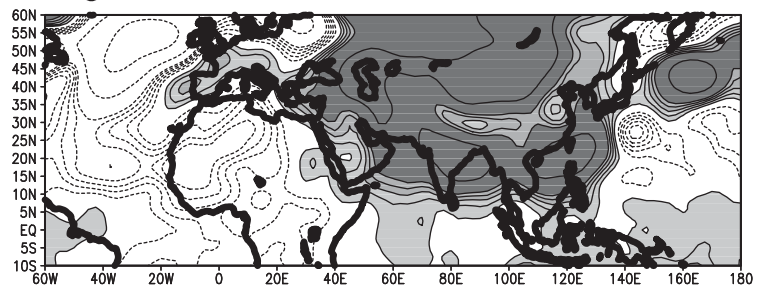

4

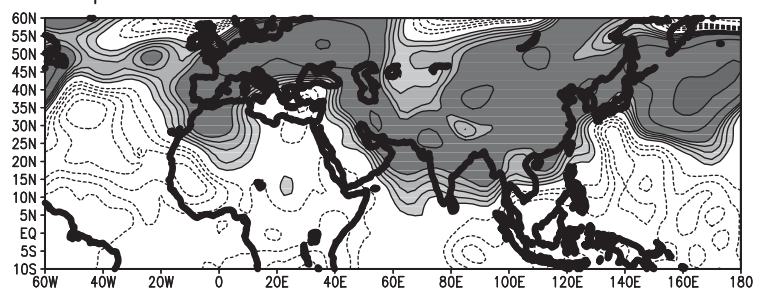

$2 \quad 6 \quad 10 \quad 40$

FIG. 10. (Continued)

which induces faster waves than convectively coupled waves in the real world.

Second, the Rossby wave pattern induced by the equatorial heat source moves northward in the Indian sector. This leads at $850 \mathrm{hPa}$ (Figs. $8 \mathrm{~b}$ and 10a on a reduced latitude domain) to a slightly reinforced cutoff between day 10 and 14 of the negative geopotential heights in the north by the positive geopotential heights moving up from the south. In consequence, an isolated cyclonic cell propagates westward over West Africa and the tropical Atlantic, with amplitudes similar to the ones observed in Figs. 2 and 10b (composite of unfiltered NCEP 850-hPa geopotential height sequence), but a bit weaker than with the fixed dipole. Then it is followed by 
the positive geopotential height structure and associated easterly winds covering West Africa at day 20. This cutoff episode is very clear in the composite unfiltered NCEP 850-hPa geopotential height sequence (Fig. 10b) between $t_{0}-6$ and $t_{0}-4$, that is, 15 days after the beginning of this sequence, close to the timing in the simulation. The negative geopotential height values are located off the coast of West Africa at about the same time in the simulation and in the composite NCEP sequence, whereas the positive geopotential height zone over the northern Africa comes mainly from the east in the simulation and more from the north in the composite NCEP sequence. This moving-dipole simulation thus shows some similarity to the observations and offers a possible explanation why the regional-scale pattern of the modulation of convection over Africa is characterized by a dominant westward propagation in the north (Fig. 1).

This set of simulations illustrates the role that the active and break phases of the Indian monsoon can play at the 25-90-day time scale in the variability of convection in the African monsoon. This influence is transferred mainly through the northern Indian heat source, which excites a cyclonic circulation propagating westward over North Africa after a cutoff due to the northward arrival of the equatorial Indian heat source and the associated intrusion of an anticyclonic ridge. Consequently, low-level westerly winds and moisture advection within the ITCZ increase over Africa, contributing to enhanced convective activity there. This has been seen by H. Annamalai (2008, personal communication) through a moist static energy budget analysis in the same kind of simulation. Horizontal advection of moisture due to a westward-propagating Rossby wave signature is the principal contributor to the enhanced diabatic heating over West Africa. This evolution leads to the establishment of the intraseasonal convective event shown in Fig. 1. A dry Kelvin wave front is also detected, initially induced by the equatorial Indian heat source. Its impact is visible through the high-level cooling and localized midlevel upward motion, which might foster convective instability, but the modulation of the low-level circulation over West Africa is very weak. This is in agreement with Bantzer and Wallace (1996) and with Maloney and Shaman's (2008) diagnostic study suggesting that the low-level signal over Africa may be more a product of convective heating than a cause. In terms of dry dynamics, the main difference from the Matthews scenario is that the dry equatorial dynamics initiated by the equatorial Indian heat source is heavily modified by the development of the dry Rossby wave pattern induced by the northern Indian heat source, leading to a dominant westward propagating signal of the OLR envelope over West Africa as convection becomes coupled with the equatorial Rossby mode. We suggest that the convective activity associated with the active/break cycle of the Indian monsoon plays a significant role in the intraseasonal modulation of the African monsoon.

The precise details of the Rossby wave propagation depend on the seasonal mean basic state chosen for these simulations, and it is possible that these results will not be reproduced exactly for all variations of basic state or all arrangements of convective sources. However, some sort of westward-spreading Gill (1980)-type response is ubiquitous for tropical dynamics and is likely to play a role in modifying the African monsoon. Further experiments are in preparation to investigate the sensitivity to variability in the flow and in the anomaly forcing. In particular, we have introduced heating field patterns in the Indian sector only, which mimics the intraseasonal phases of the Indian monsoon. We could have considered the whole heating pattern, as shown in Fig. 2, including the Southeast Asian monsoon and West Pacific sectors. This could have produced a more realistic result but would have mainly impacted the dry eastward Kelvin signal propagation (arriving earlier over Africa and possibly stronger) and not so much the equatorial Rossby signal. It should also be noted that the time scale on which the flow over West Africa responds to the northern Indian heat source is long enough to allow the coupling of convection to the equatorial Rossby mode-also for the development of African easterly waves. Further work is needed to unravel the contributions of these additional dynamical effects not considered here.

\section{Conclusions}

In this paper we have investigated the 25-90-day variability of convection in the African monsoon using the daily interpolated NOAA OLR dataset. Matthews (2004) showed that the equatorial atmospheric dynamics, through the excitation of dry Kelvin and Rossby waves by a negative diabatic heat source located over the warm pool, can explain the main mode of enhancement of convective activity in the African summer monsoon area. As a complement to Matthews' results, we have shown that this mode is not completely stationary but is characterized by a westward propagation of the OLR anomalies in its northern part. This evolution is consistent with the significant contribution of a convectively coupled equatorial Rossby wave and the MJO signal. On the other hand, convectively coupled Kelvin waves as well as the dry Kelvin wave signal have shown a relatively weak impact. However, there is more to the 
global control of the African summer monsoon than convectively coupled wave dynamics. The active/break cycle of the Indian monsoon, controlled by a northwardmoving dipole of diabatic heating in the Indian sector, also influences the African monsoon through atmospheric teleconnections. This influence can be transferred through the northern Indian heat source, which excites a Gill-type Rossby cyclonic circulation propagating westward over North Africa after a cutoff due to the northward arrival of the equatorial Indian heat source and the associated intrusion of an anticyclonic ridge. Low-level westerly winds and moisture advection within the ITCZ consequently increase over Africa. The mean time lag between an active phase over India and over Africa is about 15-20 days.

The simulations presented here have been performed with a dry primitive equation model and do not take into account the interactions between the atmospheric circulation and the deep convection, so uncertainties remain, in particular concerning the time scale of wave propagation, since convectively coupled waves are slower than dry waves. Annamalai and Sperber (2005) carried out a similar investigation on the role of regional heat sources on the active and break phases over the Asian monsoon region, using both diagnostic computations on OLR and NCEP datasets and idealized dry and moist linear model simulations. They demonstrated the efficiency of such an approach and obtained results consistent with our own. We are planning to perform further integrations with a GCM, with varying large-scale conditions furnished by a regional nudging approach toward atmospheric analyses, to further investigate these interactions.

Acknowledgments. We are thankful to the NOAACIRES Climate Diagnostics Center (Boulder, CO) for providing the NCEP-NCAR Reanalysis dataset and the Interpolated OLR dataset from their Web site at http:// www.cdc.noaa.gov/. We thank H. Annamalai and the other reviewer for their contribution to help clarify this paper. Based on French initiative, AMMA was built by an international scientific group and is currently funded by a large number of agencies, especially from France, the UK, the US, and Africa. It has been the beneficiary of a major financial contribution from the European Community's Sixth Framework Research Programme. Detailed information on scientific coordination and funding is available on the AMMA International website (http://www.amma-international.org).

\section{REFERENCES}

Annamalai, H., and J. M. Slingo, 2001: Active/break cycles: Diagnosis of the intraseasonal variability of the Asian summer monsoon. Climate Dyn., 18, 85-102.
- and K. R. Sperber, 2005: Regional heat source and the active and break phases of boreal summer intraseasonal (30-50 day) variability. J. Atmos. Sci., 62, 2726-2748.

Bantzer, C. H., and J. M. Wallace, 1996: Intraseasonal variability in tropical mean temperature and precipitation and their relation to the tropical 40-50-day oscillation. J. Atmos. Sci., 53, 3032-3045.

Cattell, R. B., 1966: The scree test for the number of factors. Multivariate Behav. Res., 1, 245-276.

Diedhiou, A., S. Janicot, A. Viltard, P. de Felice, and H. Laurent, 1999: Easterly wave regimes and associated convection over West Africa and tropical Atlantic: Results from NCEP/ NCAR and ECMWF reanalysis. Climate Dyn., 15, 795-822.

Duvel, J. P., 1990: Convection over tropical Africa and the Atlantic Ocean during northern summer. Part II: Modulation by easterly waves. Mon. Wea. Rev., 118, 1855-1868.

Folland, C. K., T. N. Palmer, and D. E. Parker, 1986: Sahel rainfall and worldwide sea temperature 1901-1985. Nature, 320, 602-607.

Giannini, A., R. Saravanan, and P. Chang, 2003: Oceanic forcing of Sahel rainfall on interannual to interdecadal time scales. Science, 302, 1027-1030, doi:10.1126/science.1089357.

Gill, A. E., 1980: Some simple solutions for heat-induced tropical circulation. Quart. J. Roy. Meteor. Soc., 106, 447-462.

Goswami, B. N., and R. S. A. Mohan, 2001: Intraseasonal oscillations and interannual variability of the Indian summer monsoon. J. Climate, 14, 1180-1198.

Grueber, A., and A. F. Krueger, 1984: The status of the NOAA outgoing longwave radiation data set. Bull. Amer. Meteor. Soc., 65, 958-962.

Hall, N. M. J., 2000: A simple GCM based on dry dynamics and constant forcing. J. Atmos. Sci., 57, 1557-1572.

- and P. D. Sardeshmukh, 1998: Is the time-mean Northern Hemisphere flow baroclinically unstable? J. Atmos. Sci., 55, 41-56.

—_, G. N. Kiladis, and C. D. Thorncroft, 2006: Three-dimensional structure and dynamics of African easterly waves. Part II: Dynamical modes. J. Atmos. Sci., 63, 2231-2245.

Hastenrath, S., 1991: Climate Dynamics of the Tropics. Kluwer Academic, $488 \mathrm{pp}$.

Hodges, K. I., and C. D. Thorncroft, 1997: Distribution and statistics of African mesoscale convective weather systems based on the ISCCP Meteosat imagery. Mon. Wea. Rev., 125, 28212837.

Janicot, S., and B. Sultan, 2001: Intra-seasonal modulation of convection in the West African monsoon. Geophys. Res. Lett., 28, $523-526$.

_, S. Trzaska, and I. Poccard, 2001: Summer Sahel-ENSO teleconnection and decadal time scale SST variations. Climate Dyn., 18, 303-320.

Kalnay, E., and Coauthors, 1996: The NCEP/NCAR 40-Year Reanalysis Project. Bull. Amer. Meteor. Soc., 77, 437-471.

Kanamitsu, M., W. Ebisuzaki, J. Woollen, S.-K. Yarg, J. J. Hnilo, M. Fiorino, and G. L. Potter, 2002: NCEP-DOE AMIP-II reanalysis (R-2). Bull. Amer. Meteor. Soc., 83, 1631-1643.

Kiladis, G. N., C. D. Thorncroft, and N. M. J. Hall, 2006: Threedimensional structure and dynamics of African easterly waves. Part I: Observations. J. Atmos. Sci., 63, 2212-2230.

Knutson, T. R., and K. M. Weickmann, 1987: 30-60-day atmospheric oscillations: Composite life cycles of convection and circulation anomalies. Mon. Wea. Rev., 115, 1407-1436.

,-- , and J. E. Kutzbach, 1986: Global-scale intraseasonal oscillations of outgoing longwave radiation and 250-mb zonal wind during Northern Hemisphere summer. Mon. Wea. Rev., 114, 605-623. 
Laing, A. G., and J. M. Fritsch, 1993: Mesoscale convective complexes in Africa. Mon. Wea. Rev., 121, 2254-2263.

—, and —, 1997: The global population of mesoscale convective complexes. Quart. J. Roy. Meteor. Soc., 123, 389-405.

Lamb, P. J., 1978a: Large-scale tropical surface circulation patterns associated with sub-Saharan weather anomalies. Tellus, 30, 240-251.

__ 1978b: Case studies of tropical Atlantic surface circulation patterns during recent sub-Saharan weather anomalies: 1967 and 1968. Mon. Wea. Rev., 106, 482-491.

Liebmann, B., and C. A. Smith, 1996: Description of a complete (interpolated) outgoing longwave radiation dataset. Bull. Amer Meteor. Soc., 77, 1275-1277.

Madden, R. A., and P. R. Julian, 1994: Observations of the 4050-day tropical oscillation-A review. Mon. Wea. Rev., 122, 814-837.

Maloney, E. D., and D. L. Hartmann, 2000: Modulation of eastern North Pacific hurricanes by the Madden-Julian oscillation. $J$. Climate, 13, 1451-1460.

_ , and J. T. Kiehl, 2002: MJO-related SST variations over the tropical eastern Pacific during Northern Hemisphere summer. J. Climate, 15, 675-689.

_- and J. Shaman, 2008: Intraseasonal variability of the West African monsoon and Atlantic ITCZ. J. Climate, 21, 28982918.

Mathon, V., and H. Laurent, 2001: Life cycle of Sahelian mesoscale convective cloud systems. Quart. J. Roy. Meteor. Soc., 127, 377-406.

— $—$, and T. Lebel, 2002: Mesoscale convective systems rainfall in the Sahel. J. Appl. Meteor., 41, 1081-1092.

Matsuno, T., 1966: Quasigeostrophic motion in the equatorial area. J. Meteor. Soc. Japan, 44, 25-42.

Matthews, A. J., 2000: Propagation mechanisms for the MaddenJulian oscillation. Quart. J. Roy. Meteor. Soc., 126, 26372652.

_ 2004: Intraseasonal variability over tropical Africa during northern summer. J. Climate, 17, 2427-2440.

Mekonnen, A., C. D. Thorncroft, A. R. Aiyyer, and G. N. Kiladis, 2008: Convectively coupled Kelvin waves over tropical Africa during the boreal summer: Structure and variability. J. Climate, 21, 6649-6667.

Milliff, R. F., and R. A. Madden, 1996: The existence and vertical structure of fast, eastward-moving disturbances in the equatorial troposphere. J. Atmos. Sci., 53, 586-597.

Mounier, F., and S. Janicot, 2004: Evidence of two independent modes of convection at intraseasonal timescale in the West African summer monsoon. Geophys. Res. Lett., 31, L16116, doi:10.1029/2004GL020665.

_ - G. N. Kiladis, and S. Janicot, 2007: Analysis of the dominant mode of convectively coupled Kelvin waves in the West African monsoon. J. Climate, 20, 1487-1503.

_ - S. Janicot, and G. N. Kiladis, 2008: The West African monsoon dynamics. Part III: The quasi-biweekly zonal dipole. $J$. Climate, 21, 1911-1928.

Murakami, T., L.-X. Chen, A. Xie, and M. L. Shresha, 1986: Eastward propagation of 30-60 day perturbations as revealed from outgoing longwave radiation data. J. Atmos. Sci., 43, 961-971.
Newell, R. E., and J. E. Kidson, 1984: African mean wind changes between Sahelian wet and dry periods. J. Climatol., 4, 27-33.

Nicholson, S. E., 1978: Climatic variations in the Sahel and other African regions during the past five centuries. J. Arid Environ., 1, 3-24.

North, G. R., R. F. Bell, R. F. Cahalan, and F. J. Moeng, 1982: Sampling errors in the estimation of empirical orthogonal function. Mon. Wea. Rev., 110, 699-706.

Reed, R. J., D. C. Norquist, and E. E. Recker, 1977: The structure and properties of African wave disturbances as observed during Phase III of GATE. Mon. Wea. Rev., 105, 317-333.

Richman, M. B., 1986: Rotation on principal component. J. Climatol., 6, 293-335.

Rodwell, M. J., and B. J. Hoskins, 1996: Monsoons and dynamics of desert. Quart. J. Roy. Meteor. Soc., 122, 1385-1404.

Roundy, P. E., and W. M. Frank, 2004a: A climatology of waves in the equatorial region. J. Atmos. Sci., 61, 2105-2132.

, and - 2004b: Effects of low-frequency wave interactions on intraseasonal oscillations. J. Atmos. Sci., 61, 3025-3040.

Rowell, D. P., 2001: Teleconnections between the tropical Pacific and the Sahel. Quart. J. Roy. Meteor. Soc., 127, 1683-1706.

, C. K. Folland, K. Maskell, and M. N. Ward, 1995: Variability of summer rainfall over tropical North Africa (1906-1992): Observations and modelling. Quart. J. Roy. Meteor. Soc., 121, 669-704.

Rui, H., and B. Wang, 1990: Development characteristics and dynamic structure of tropical intraseasonal convective anomalies. J. Atmos. Sci., 47, 357-379.

Straub, K. H., and G. N. Kiladis, 2002: Observations of convectively coupled Kelvin waves in the eastern Pacific ITCZ. J. Atmos. Sci., 59, 30-53.

Sultan, B., and S. Janicot, 2003: The West African monsoon dynamics. Part II: The "preonset" and "onset" of the summer monsoon. J. Climate, 16, 3407-3427.

_ _ - and A. Diedhiou, 2003: The West African monsoon dynamics. Part I: Documentation of intraseasonal variability. J. Climate, 16, 3389-3406.

Thompson, R. M., Jr., S. W. Payne, E. E. Recker, and R. J. Reed, 1979: Structure and properties of synoptic-scale wave disturbances in the intertropical convergence zone of the eastern Atlantic. J. Atmos. Sci., 36, 53-72.

Thorncroft, C. D., and B. J. Hoskins, 1994a: An idealized study of African easterly waves. Part I: A linear view. Quart. J. Roy. Meteor. Soc., 120, 953-982.

— and - 1994b: An idealized study of African easterly waves. Part II: A nonlinear view. Quart. J. Roy. Meteor. Soc., 120, 983-1015.

Ward, M. N., 1998: Diagnosis and short-lead time prediction of summer rainfall in tropical North Africa at interannual and multidecadal timescales. J. Climate, 11, 3167-3191.

Wheeler, M., and G. N. Kiladis, 1999: Convectively coupled equatorial waves: Analysis of clouds and temperature in the wavenumber-frequency domain. J. Atmos. Sci., 56, 374-399.

, - - and P. J. Webster, 2000: Large-scale dynamical fields associated with convectively coupled equatorial waves. $J$. Atmos. Sci., 57, 613-640.

Yasunari, T., 1981: Structure of an Indian summer monsoon system with around 40-day period. J. Meteor. Soc. Japan, 59, 336-354. 